Seton Hall University eRepository@Seton Hall

Spring 5-16-2015

\title{
Health-Related Beliefs, Practices, and Experiences of Migrant Dominicans in the Northeastern United States
}

Constance Sobon Sensor

constance.sensor@student.shu.edu

Follow this and additional works at: https://scholarship.shu.edu/dissertations

Part of the Community-Based Research Commons, International and Intercultural Communication Commons, Medicine and Health Commons, Psychiatric and Mental Health

Nursing Commons, Public Health and Community Nursing Commons, and the Social and Cultural Anthropology Commons

\section{Recommended Citation}

Sobon Sensor, Constance, "Health-Related Beliefs, Practices, and Experiences of Migrant Dominicans in the Northeastern United States" (2015). Seton Hall University Dissertations and Theses (ETDs). 2047.

https://scholarship.shu.edu/dissertations/2047 


\section{HEALTH-RELATED BELIEFS, PRACTICES, AND EXPERIENCES OF MGRANT DOMINICANS IN THE NORTHEASTERN UNITED STATES}

BY

CONSTANCE SOBON SENSOR

Dissertation Committee

Dr. Judith Lothian, Chair

Dr. Dula F. Pacquiao

Dr. Jean Rubino

Approved by the Dissertation Committee:

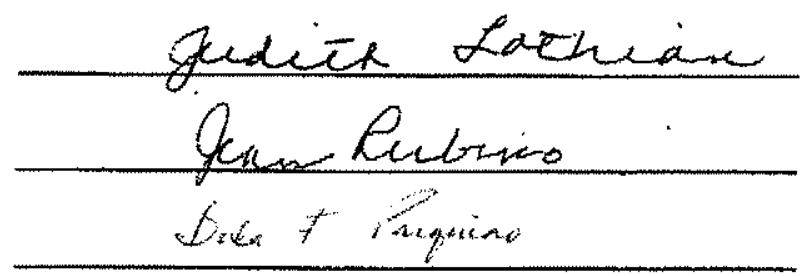

Date: $3 / 3 / 15$

Date: $3 / 3 / 15$

Date: $3 / 2 / 15$

$\stackrel{7}{7}$

Submitted in partial fulfillment of the

Requirements for the degree of Doctor of Philosophy in Nursing

Seton Hall University

2015 
Copyright (C) Constance Sobon Sensor 2015 


\section{ACKNOWLEDGEMENTS}

I deeply appreciate the many people that believed in me and offered their encouragement and support. I am thankful for the financial support of Gamma $\mathrm{Nu}$ Chapter (Seton Hall University) and Kappa Eta Chapter (New Jersey City University) of Sigma Theta Tau, the International Honor Society of Nursing, and the Englewood Hospital School of Nursing Alumnae Association (New Jersey), who partially funded this research with grants and scholarship awards.

I gratefully acknowledge my dissertation committee, Dr. Judith A. Lothian, Chair, Dr. Dula F. Pacquiao, and Dr. Jean Rubino, for your wisdom, commitment, and scholarly expertise every step of the way.

Dr. Lothian, I am forever grateful for your ability to listen and help me to amplify the voices of this migrant Dominican group through my writing and revisions until my goal was achieved. You devoted tireless energy to my work, and supported me in every way through the challenges in my personal life that threatened to make me lose sight of my goal. Thank you is a small word for the gratitude I owe you. I know that we are both joyful that I completed this work!

Dr. Pacquiao, you have been my mentor. My passion for transcultural nursing and research was ignited in your classes at Kean University a long time ago. Your continuous encouragement, from the moment we met, planted the seed for me to grow professionally as a transcultural nurse and scholar. I will never forget the time you 
spent to make sure I understood the research process as we analyzed data together at your kitchen table when I was a master's student. You inspired me to become a Certified Transcultural Nurse, and encouraged me to use these skills to make a difference in the lives of others through research and dissemination of knowledge. I am grateful to have your wisdom, scholarship, transcultural nursing expertise, and guidance in this research endeavor.

Dr. Rubino, thank you for reviewing my work and helping me to express my ideas clearly and concisely, in ways that were thoughtful and relevant.

Alana Cueto, you played a major role in helping me with this research. You recruited participants for the study and provided a safe place for the focus groups to meet in your home. If it were not for your social relationship with the participants, and your generosity as a hostess for the meeting place, it would have taken me much longer to find participants and collect the data I needed for this research. You were the gatekeeper that assisted me in gaining entrée to this group of Dominicans, and you also took on the role of interpreter and translator, and acted as a cultural broker between me and the Dominican participants in this study. Your multiple roles beyond serving as an interpreter enabled me to build trust with the participants, so that they were willing to share information with me in a way that may not have happened without your assistance.

I am grateful for my bilingual colleagues who served as interpreters and translators, Arlene Patrick and Wendy Watson, and of course, Alana Cueto. You eagerly gave your time, talent, and expertise with Dominican language and culture to 
assist me with this study. Your perspective guided me in collecting and interpreting the data, and added to the depth of the study.

I appreciate the input from Dr. Munira Wells and Dr. Shelia Linz, who read my dissertation and participated in my defense. I enjoyed our scholarly discussion and value the time you spent with my work.

My husband, J. Timothy Sensor, I am so grateful for your loving presence in my life. Thank you for giving me the time and space I needed to complete this work, and for the many sacrifices you made to help me finish. You have always been "the wind beneath my wings." I welcome you to celebrate the completion of this research with me! 


\section{DEDICATION}

I dedicate this dissertation to my family for their endless love and support, especially my husband, J. Timothy Sensor, and my sons Christopher, Ted, James, and Brian, and my grandson Charlie, with the hope that you will keep a lifelong love of learning, pursue your passion and your dreams, and seek opportunities to make a difference in the world.

Most importantly, I dedicate this dissertation to the humble group of migrant Dominicans who came to teach me about themselves and their lives, their healthrelated beliefs and practices, and the ways that we can improve professional health care for Dominicans living in the United States. I am honored to give voice to what you told me in this dissertation. 
Table of Contents

ACKNOWLEDGEMENTS ........................................ 3

DEDICATION..................................................... 6

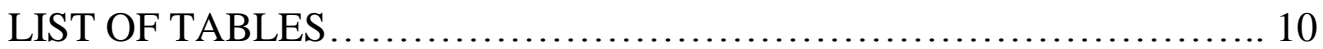

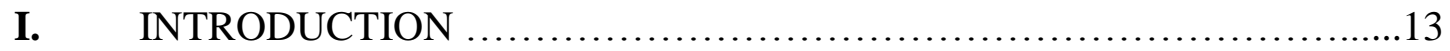

Migration and Moving On

Aim of the Study

Phenomenon of Interest

Theoretical Rationale

Research Question

Significance of the Study

II. REVIEW OF THE LITERATURE ................................22

The Migrant Experience with Professional Health Care

Studies of Dominicans

Studies in the Dominican Republic

Studies in the New York City Area

Gaps in the Literature

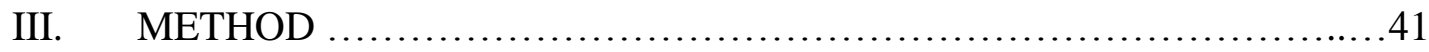

Design of the Study

Gaining Access and Establishing Rapport

The gatekeepers

Building rapport

Working with Interpreters and Translators

Selection

Preparation

Cultural brokers

The Participants

Eligibility

Recruitment

Demographic survey

Setting

Ethical Considerations 
Data Collection

Composition of the focus group

Procedure

Data Analysis

First phase: Collecting, describing, and documenting raw data

Second phase: Identification and categorizing of descriptors and components

Third phase: Patterns and contextual analysis

Fourth phase: Major themes, research findings, theoretical

formulations, and recommendations

Controlling Bias

Establishing and Maintaining Trustworthiness

IV. FINDINGS

The Participants

Age and gender

Marital status and children

Time in the U.S., language, and literacy

Education and employment

Households and income

Results

Themes

Theme One: Stress Affects Health and Well-Being

Differences between life in the Dominican Republic and the

United States

Coping with Stress

Theme Two: Family Support and Faith in God are Essential for Healing and Promoting Health and Well-Being

Family Support

Faith in God

The Power of Prayer

Our Relationship with the Priest

Theme Three: Migrant Dominicans Use Both Folk Care and Professional

Care to Treat Illness and Promote Healing, Health and Well-Being

Natural Home Remedies

Magico-Religious Practices

Theme Four: Perceptions about the Quality of Professional Care Are

Affected by Access to Care, Cost, Communication and Expressions of Caring Practices

Access to Care

The Cost of Professional Care

Communication with Providers

Experiences, Expectations, and Satisfaction with Professional Care 
V. DISCUSSION 101

Theme One: Stress Affects Health and Well-Being

Theme Two: Family Support and Faith in God are Essential for Healing, and Promoting Health and Well-Being

Theme Three: Migrant Dominicans Use Both Folk Care and Professional Care to Treat Illness and Promote Healing, Health, and Well-Being

Theme Four: Perceptions about the Quality of Professional Care Are Affected by Access to Care, Cost, Communication and Expressions of Caring Practices

VI. IMPLICATIONS FOR NURSING PRACTICE, RESEARCH AND EDUCATION

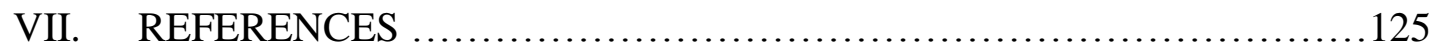

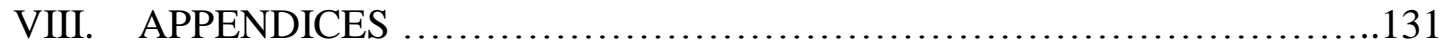

A. EXAMPLE OF INTERVIEW INQUIRY GUIDE

B. CONFIDENTIALITY AGREEMENT FOR INTERPRETERS

C. RECRUITMENT SCRIPT FOR OUTREACH WORKERS

D. DEMOGRAPHIC SURVEY QUESTIONS

E. APPROVAL FROM INSTITUTIONAL REVIEW BOARD 136

F. INFORMED CONSENT IN SPANISH 138

G. INFORMED CONSENT IN ENGLISH 141 


\section{LIST OF TABLES}

1 Demographic Snapshot of the Participants.................................66

2 Findings Using Leininger's Phases of Ethnonursing Analysis

for Qualitative Data ................................................. 70

3 Strategies for Culturally Responsive Care Using Leininger's Three

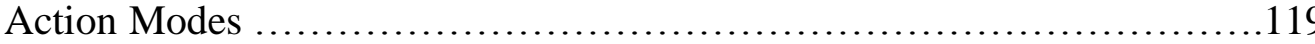




\begin{abstract}
Purpose: This study aimed to discover and describe migrant Dominican cultural beliefs and practices related to health, the ways that migrant Dominicans take care of their health in their new environment, and their experience with professional health care in the Northeastern United States.

Design: This descriptive qualitative study was guided by Leininger's Theory of Culture Care Diversity and Universality and four-phase analysis method. The healthrelated beliefs, practices and experiences of a convenience sample of 15 self-identified adult Dominicans living in the United States for six months or more were explored in three focus groups, assisted by trained culturally appropriate interpreters.
\end{abstract}

Findings: Data analysis of focus group transcripts and observations revealed four themes: (a) stress affects health and well-being, (b) family support and faith in God are essential for healing, and promoting health and well-being, (c) migrant Dominicans use both folk care and professional care to treat illness and promote healing, health, and well-being, and (d) perceptions about the quality of professional care are affected by access to care, cost, communication and expressions of caring practices.

Discussion and Conclusion: Implications and recommendations for nursing practice, education and research are discussed. Design and implementation challenges from this study, and strategies used to bridge cultural and linguistic barriers, may guide others in planning research with similar populations. 
Keywords: Dominicans, health, cultural beliefs, cultural practices, folk care, professional care, Culture Care Theory, interpreters, migrants 


\section{Chapter I INTRODUCTION}

I first became interested in exploring the cultural health beliefs and practices of Dominicans while participating in a health-related service leadership project in the bateyes (the villages where the workers from the sugar cane plantations live) in the rural areas of the Dominican Republic outside of Santo Domingo, during the summer of 2007. During this trip, nurses partnered with an established community group in the Dominican Republic that helped to build schools and promote education. Just as this group had worked mano y mano with the people to build schools, we, as nurses, worked together with the Dominicans, mano y mano, to set up health clinics and provide professional health care in rural areas outside of Santo Domingo.

While preparing for this trip, I began to investigate the traditional beliefs and practices of this population through reviewing literature and through conversations with others who had experience working with Dominicans in the bateyes. The preparatory knowledge I gathered was reinforced through my interactions with the Dominicans in their own native environment. Beginning with cultural awareness of my own bias, my cultural encounters led me to cultural knowledge, cultural skill and cultural desire to continue learning about this population (Campinha-Bacote, 2003).

I was especially touched by the disparities I witnessed in the poverty-laden bateyes. When I returned from this mission trip, I wanted to learn more about 
Dominican culture, and their health beliefs and generic (folk) practices; so that I could more fully understand what I witnessed in their country. From my own experience, as I worked mano y mano (hand in hand) with the Dominican people, on their batey, in their country, I began to learn about the emic (insider's) worldview of the Dominicans, that was both similar and different from my etic (outsider's) perspective. I needed to gain understanding of their health-related beliefs and practices, the perceived cause of their illness, and what they believed was necessary to restore their health if I wanted to see compliance with treatment. I was profoundly aware that in this place, healing does not occur with professional care and biomedical science alone. I observed a high incidence of diabetes and hypertension, and yet these Dominicans managed their health in ways that worked for them.

It was obvious to me that the professional practices used in the United States could not be taught to people in this area of the Dominican Republic in the same way. When I reflected on the typical education for managing diabetes in the United States, I realized that it would be irrelevant in this environment. Food choices were limited to what was fresh at hand, such as mangoes and bananas growing on the trees, or the eggs in the chicken coop. Portion control was not part of the discussion, as there was never enough food. Exercise was a way of life; the people worked outside and walked everywhere. People took medicine only if they were not feeling good, as it was hard to get and expensive. It was clear that these people were managing their health in ways that were different. 
I was aware that Dominicans migrate to New York and New Jersey in large numbers, and based on what I had experienced, I wondered how they managed their health in this new environment. It seemed natural for me to pursue a study that included a transcultural nursing approach to exploring and expanding research focused on evaluating and eliminating health and health care disparities for Dominicans living in the Northeastern United States. I was inspired to continue my journey of discovery and service that began in Dominican Republic with this population in the United States. Accordingly, migrant Dominicans became the focus of this culture care research.

\section{Migration and Moving On}

It is expected that the rapidly growing migrant Dominican population in the northeastern United States will need professional health care due to significant health issues reported in the literature. More than three-quarters of the Dominican population $(78 \%)$ reside in the northeastern United States, and the largest number reside in New York $(647,787)$ and New Jersey $(197,922)$; followed by Florida $(172,451)$;

Massachusetts (103,292); Pennsylvania (62,348); and Rhode Island (35,000) (Ennis, Rios-Vargas, \& Albert, 2011). Between 1990 and 2000, the number of foreign born from the Dominican Republic in the United States increased by $98 \%$ (U.S. Census Bureau, 2003 a; U.S. Census Bureau, 2003 b). The trend continued between 2000 and 2010, with an $85 \%$ increase in the Dominican population, from 765,000 to 1.4 million (Ennis et al., 2011). In northern Manhattan, this population also bears the burden of a higher incidence of diabetes and related health risk factors than the general population 
of the United States (Getaneh, Michelen, \& Findley, 2008). There is a higher prevalence of diabetes, hypertension, and obesity in first generation Dominicans, compared to other Latino populations living in New York City (Getaneh, et al., 2008). According to Aponte (2009), the literature reporting on diabetes is focused on Hispanics as a homogenous group, and "while such studies have yielded important data on Hispanics in general and selected subgroups, they have failed to differentiate issues related to diabetes for unique Hispanic subgroups" (p.25). Florez, Aguirre, Viladrich, Cespedes, De La Cruz, \& Abraido-Lanza (2009), who studied the influence of cultural beliefs and practices on health-seeking behaviors of Dominican women related to breast cancer, also support the idea of unique cultural beliefs and practices among Latino subgroups in the United States by reporting that "cultural differences shaped by national origin and distinct historical and sociopolitical trajectories characterize each population" (p. 292). Although Hispanics and Latinos may share a common language, they do not collectively share all of the same cultural beliefs and practices, and most studies do not differentiate the unique subgroups of Hispanics and Latinos in the research (Zsemlik \& Fennell, 2005).

The studies done in New York City indicate that migrant Dominicans make adaptive changes in their health practices in the United States, but their generic (folk) care is largely unknown to people outside of their community (Allen, et al., 2000; Florez et al., 2009; Fugh-Berman et al., 2004; Ososki et al., 2002; Shedlin \& Shulman, 2004; Vandebroek et al., 2010). In addition, professional health care may be unfamiliar to rural Dominicans who migrate to urban areas of the U.S. (Shedlin \& 
Shulman) When migrants seek professional health care that is unfamiliar to them, they may perceive that their own cultural beliefs and practices are not well understood or respected by "outsiders" or "others," such as health care providers, and this factor may contribute to health disparities (Ngo-Metzger et al., 2003; Purnell, 1999; Purnell, 2001; Sensor, 2006; Suurmond \& Seeleman, 2005; Warda, 2000; Zoucha, 1998). The literature suggests that nurses may have limited knowledge about unique cultural health beliefs and practices that can present barriers for migrant clients seeking professional care (Aponte, 2009; Caballero, 2007; Carter, Pugh, \& Monterrosa, 1996; Sensor, 2006; Zsemlik \& Fennell, 2005; Zoucha, 1998); therefore, more culturally specific research with Dominicans is needed.

\section{Aim of the Study}

The aim of this descriptive qualitative study was to discover and describe the health-related beliefs, practices, and experiences of migrant Dominicans in the northeastern United States.

\section{Phenomenon of Interest}

The phenomenon of interest for this study is Dominican cultural beliefs and practices related to health, ways that Dominican migrants take care of their health, and their experience with professional health care in the United States.

\section{Theoretical Rationale}

The central purpose of Leininger's Culture Care Theory (1997) is to discover, document, interpret, explain and predict some of the multiple factors influencing care from an emic (inside the culture) and an etic (outside the culture) view as related to 
culturally based care. Therefore this study used assumptions from Culture Care Theory, to discover and describe the health-related beliefs, practices and experiences of migrant Dominicans in the United States.

Leininger (1997) describes culture care as a specific way that people view care and caring behaviors that varies among cultures. It is related to subjectively and objectively learned and transmitted values, beliefs, and patterned lifeways that assist, support or facilitate or enable people to maintain their well being or health, or to improve their human condition or lifeways, or to deal with illness, handicaps or death (Leininger, 1997). By comparison, Leininger (1997) describes two different kinds of care, generic and professional care. Professional care refers to formally taught scientific knowledge and skills, as practiced by licensed professionals, such as nurses (Leininger, 2001). Leininger used the term generic care to include "all traditional, folk, lay, indigenous, local, home or alternative caring practices that have been used by people over time and have been valued and known as first use, naturalistic, familiar, and beneficial practices" and predicted that "generic care was essential to professional nursing as it is one of the oldest modes of caring for human beings worldwide" (Leininger, 1997, p. 36). "The theory of culture care predicts that if nurses fully understood generic care in different cultures and used it appropriately with professional care, one would find therapeutic or beneficial healing outcomes" (Leininger, 1997, p.36).

This study was guided by assumptions from Leininger's (1997) Theory of Culture Care Diversity and Universality (Culture Care Theory). The following 
assumptions that guided this study were derived from the thirteen assumptive premises of the Culture Care Theory (Leininger, 2001).

1. Therapeutic nursing care can only occur when client culture care values, expressions, or practices are known and used explicitly to provide human care practices.

2. Culturally responsive, specific care modes are essential to the health and wellbeing of people served by nurses worldwide.

3. Culture care practices of migrant Dominicans can be identified within the Latino community, showing some similarities and differences between migrant Dominican and American practices.

4. Professional health care providers are aware of generic (folk) and professional views of care of Dominicans that influence management of health and wellbeing.

\section{Research Question}

What are the health-related beliefs, practices, and experiences of migrant Dominicans in the Northeastern United States?

\section{Significance of the Study}

The meaning of health and the reasons for seeking professional health care may vary among ethnic groups dependent on their cultural beliefs and practices. In this context, health can be viewed as "a state of well-being or restorative state that is culturally constituted, defined, valued, and practiced by individuals or groups, that enable them to function in their daily lives" (Leininger, 1997, p.38). Globally, people 
have health beliefs and practices that are diverse, or different, and some that are universal, or the same (Leininger, 1997). As our society becomes more global, nurses are challenged to have knowledge of the cultural health beliefs and practices of the populations they serve in order to promote healing and well-being.

Locally, the prevalence of diabetes and related health issues in the Dominican population is higher in comparison to other Latino populations living in New York City (Getaneh et al., 2008). First generation Dominicans living in northern Manhattan have higher rates of diagnosed diabetes than Mexican Americans (13 vs. 10.4\%, respectively); undiagnosed diabetes (3.4 vs. 3.0\%); hypertension (30.8 vs. 19.1\%); and obesity (58.2 vs. 34.4\%) (Getaneh et al., 2008). The prevalence of diagnosed diabetes in Dominicans exceeded comparable rates among U.S. Latinos dominated by Mexican Americans, while their hypertension rate exceeded both U.S. Latino and African American rates (Pabon-Nau, Cohen, Meigs, \& Grant, 2010). Dominicans were more obese than either U.S. Latinos or African Americans. In this study of Dominicans in northern Manhattan (Getaneh et al., 2008), 17\% of the Dominicans that were tested had diabetes, $20 \%$ had impaired fasting glucose levels, and $75 \%$ were overweight or obese. While greater than eighty percent of the study population had clinical encounters in the previous twelve months, twenty nine percent were unaware they had diabetes. The Institute of Medicine of the National Academies (IOM) (2004) reported that these disparities are not accounted for by level of access to care, socioeconomic status, age, stage of presentation, or existing co-morbidities, and can be found in multiple health care settings (managed care, public, private, teaching and community 
centers). Therefore, because of the rapidly growing Dominican population in the United States, and this IOM report, it is important for healthcare providers to gain knowledge about the health-related beliefs, practices, and experiences of this population in order to provide culturally specific professional care in local Dominican communities.

Furthermore, it is reported that all migrants to the United States are healthier in their country of origin (Carter et al., 1996). In fact, studies comparing migrant populations with native populations reveal a consistent linkage of type 2 diabetes with the American lifestyle (Agency for Healthcare Research \& Quality (AHRQ), 2001). As an example, diabetes is the sixth leading cause of death in the United States, and all minorities in the United States for which data exist, have a higher prevalence of diabetes than do residents of their countries of origin (Carter et al., 1996). The literature supports that this is true for Dominicans living in the New York City area (Getaneh et al., 2008), yet migrant Dominican health-related beliefs, practices and experiences in their new environment remain largely unknown to people outside of the Dominican community. Therefore, the knowledge gained from this study may be beneficial in planning culturally specific risk-reduction interventions for migrant Dominicans related to known health disparities. 


\section{Chapter II}

\section{REVIEW OF THE LITERATURE}

\section{The Migrant Experience with Professional Health Care}

Cagle (2006) states that caring interactions that meet the ethical principle of beneficence (above all, do good) may be challenging in cases where the client and the nurse are from different ethnic or cultural backgrounds, when their cultural values influence the interpretation of caring interactions of both parties. Several qualitative studies were found that explore the concepts of respect, and caring and non-caring behaviors of the provider from the migrant patient's perspective and explored differences between the health care provider and the patient regarding attitudes and beliefs about the concept of health and uses of folk medicine (Ngo-Metzger et al., 2003; Purnell, 1999; Purnell, 2001; Suurmond \& Seeleman, 2005; Warda, 2000; Zoucha, 1998).

Purnell's studies $(1999,2001)$ were identical in design using the 44-item Hispanic Health Belief and Meaning of Respect Questionnaire to study Central American practices for health promotion and wellness, disease and illness prevention, and the meaning of respect afforded them by health care practitioners. The 1999 research collected data from 50 Panamanian and 20 Panamanian-American participants, and the 2001 study collected data from 51 Guatemalans. In both studies, the data were collected by people trained by the principal investigator who were fluent 
in Spanish and were familiar with the native culture. In summarizing the studies, similar findings emerged. Participants reported diet, exercise, hot/cold and wet/dry balance, self-care, good hygiene, using herbs and herbal teas, and seeing physicians, nurses, curanderos or priests to maintain health. Guatemalans also reported using a masseuse for health maintenance or treatment of illness. In the study of Guatemalans, bad health was attributed to eating bad food, poor hygiene, or "God's will," poverty, not exercising, or living in a farming community (Purnell, 2001, p.46).

Verbal and especially non-verbal communication that demonstrated respect was valued. Examples that illustrated respect were reported as: "the way the health care provider talks to me," and "gives me complete information," "has presence," "sincere," "friendly," "worries about me when I'm ill," "is completely dedicated to me at the time of treatment," "treats me like a human being," and "touches me only where it is necessary" (Purnell, 1999, p.336). Non-verbal communication that was perceived as disrespectful included the following: "gives little attention," "is insincere," "ignores me when I call," "does not look me in the eye," and "does not greet you" (Purnell, 1999, p.336).

Suurmond \& Seeleman (2006) reviewed the literature, and identified four conceptual barriers to shared decision-making between physicians and immigrant patients. The four conceptual barriers identified are: different linguistic background, different values about health and illness, different role expectations, and prejudice and not speaking to each other in an unbiased manner. These conceptual barriers were compared with the results of semi-structured interviews with purposively selected 
physicians $(n=18)$ and immigrant patients $(n=13)$. The immigrant patients were Turkish, Moroccan, Surinamese, Afghan, Bosnian, Ghanaian, Somalian, Antillean, and Iranian. They ranged in age from 20 to 78, with equal gender distribution of men and women, and had been living in the Netherlands from 3 to 18 years. The researchers concluded that due to the barriers described, the transfer of information, the formulation of the diagnosis, and the discussion of treatment options are at stake and the shared decision-making process is impeded by these barriers. They recommended steps be taken to raise awareness among physicians to overcome these barriers.

Warda (2000) used focus-group interviews with Mexican American Registered Nurses and Mexican American lay recipients of health care to explore the participants' subjective perceptions regarding the indicators of culturally competent care. The University of California, San Francisco, Committee on Human Research approved a waiver of need for signed consent to conduct this study. She conducted four focus groups with a total of 22 Mexican American participants. All of the focus groups were conducted in community based organizations such as a college campus or a conference room in a community church. The influence of culture remained strong for the Mexican American Registered Nurses despite their professional nursing experience and knowledge of the Western biomedical system. Warda's findings indicate that health care providers need to take into account personal, cultural, and environmental context when providing care to Mexican Americans. The focus group participants identified culturally defined concepts (personalismo or formal friendliness 
and valuing), cognitive/perceptive concepts (knowledge of U.S. health care system), and system-related concepts (system barriers such as acknowledgement of the importance of family involvement, respect for use of cultural beliefs and practices like folk medicine, emphasis on interpersonal rapport, and understanding of life circumstances and economic constraints) related to their perception of culturally competent care. The Mexican American participants emphasized respect, caring, understanding and patience in health care encounters that make it possible for them, as recipients of health care, to deal with health-related issues successfully or on similar terms with the US population.

Zoucha's (1998) qualitative study using the ethnonursing method, explored the care experiences, views, patterns and meanings of Mexican Americans who had received professional nursing care. Fifteen Mexican American key informants and 25 family/friends, nurses, and other health care professional general informants were interviewed in a community based out-patient surgery clinic in a large metropolitan area in the southwestern United States. Three major themes emerged. Personal, friendly, and respectful care expressions and practices from registered nurses were expected and valued by Mexican Americans. Nurses were viewed as uncaring if they did not combine Mexican American generic care values with professional nursing care practices. Confidence (confianza) was desirable in the care of Mexican Americans (Zoucha, 1998, p. 34).

According to Zoucha (1998), Mexican Americans described care as personal and friendly when a nurse was attentive and took time with them, as well as trying 
some words to communicate in Spanish. Mexican American informants explained that they always have confidence in family or friend caregivers because they are compadres, and the nurse must earn the confidence of the Mexican American client when providing professional care. Confidence involves the process of the nurse becoming personal with the client, leading to health and well- being for the Mexican American client (p. 40). "This confidence is shared by the nurse and client, and empowers both to take responsibility for health promoting actions and decisions" (Zoucha, 1998, p. 40). Dominant culture care values identified from this research include confidence, attention, respect, concern, spending time, communicating in Spanish, and love.

Ngo-Metzger et al. (2003) conducted a qualitative study using focus groups to examine factors contributing to quality of care from the perspective of Chinese and Vietnamese-American patients with limited English language skills. A total of 122 Chinese and Vietnamese American patients were interviewed in 12 single gender focus groups of 6 to 12 participants per group, by bilingual interviewers using a standardized, translated moderator guide. Open ended questions were developed to elicit patients' views of the following topics: positive and negative experiences with medical care in the United States, patient/provider communication, use of interpreters, role of family in patient's care, and use of non-Western medical practices.

Content analysis revealed several important findings. Chinese and VietnameseAmerican patients wanted to discuss the use of non-Western medical practices with their providers but encountered significant barriers (Ngo-Metzger et al., 2003). They 
viewed providers' knowledge, inquiry and nonjudgmental acceptance of traditional Asian medical beliefs and practices as part of quality care. From the patients' perspective, important aspects of quality for them include providers' respect for traditional health beliefs and practices, access to professional interpreters, and assistance in obtaining social services.

\section{Studies of Dominicans}

Several studies specific to Dominican culture and health were found in the literature. Of interest, all of the studies conducted in the Dominican Republic were done in rural areas (Babbington, Kelley, Patsdaughter, Soderberg \& Kelley, 1999; Holt, 2000; Nui et al., 2011; Schumacher, 2010), while all of the studies that were conducted with migrant Dominicans were from populations living in the New York City area of the United States (Allen et al., 2000; Florez et al., 2009; Fugh-Berman et al., 2004; Ososki et al., 2002; Shedlin \& Shulman, 2004; Vandebroek et al., 2010).

\section{Studies in the Dominican Republic}

Babbington et al. (1999) conducted a study in the rural Dominican Republic to gain knowledge about health beliefs and health care encounters. Findings from six focus group interviews indicated health beliefs fall into the two major categories of physical and magico-religious. Findings reported that the chief physical complaints were not life-threatening, however, they were of utmost importance to the Dominicans in their daily lives, and the presence of caring health professionals was deeply appreciated. The authors contend that "having a group of Western health care providers that would listen and respond to their concerns offered validation and 
support for Dominicans who have been virtually ignored by the misdirected health care system in their native land" (p. 24).

Babbington et al. (1999) reported that disease and illness were often attributed to supernatural causes such as bad luck, black magic, voodoo and spells, and many of the recipes for dealing with the magico-religious causes of illness focused on the color red for protection from evil spirits. "Practices such as prayer, the use of sacraments, and paying homage to special saints and holy images were viewed as integral to good health and disease prevention and treatment" (p. 24). This study reflects influences of their ethnohistory on Dominican health practices, and illustrates facets of cultural health beliefs, such as supernatural causes of illness, and health protection derived from prayer or "wearing something red" to ward off the evil spirits that cause illness.

Another example of prayer for healing was documented in a study done in the Dominican Republic that examined how patients with advanced arthritis are affected and cope with their disease (Nui et al., 2011). The study describes the OpWalk Boston program that selects eligible patients in the DR for joint replacement surgery by a team that is sent to the DR from Boston to perform the surgeries. The participants were recruited in the DR and participated in the study while they were pre-op patients in the hospital awaiting their joint replacement surgeries. A convenience sample of eighteen economically disadvantaged Dominican patients with advanced knee and/or hip arthritis were interviewed and audio taped in Spanish on a one-to-one basis using a moderator's guide that included topics such as understanding of the disease etiology, support networks, and coping mechanisms. Similar to the 
findings of Babbington et al. (1999), these participants reported religious and environmental theories of disease etiology, stating their illness had been caused by God's will or through repeated contact with water including bathing, spending time outdoors in the rain, and performing chores involving water, such as washing dishes or clothes. Arthritis represented God's way of testing their faith, and they trusted that demonstrating their faith would ultimately convince God to cure their illness. According to one patient, "This problem is a test. A test. It's a test to see if I can continue fighting or not" (p. 5). All participants experienced physical limitations from their arthritis, but the social effects of the disease were gender specific. Women noted interference with home making and church-going activities, while men complained of disruption with occupational roles. The coping strategies used were reflective of their beliefs about the cause of arthritis and included prayer and avoidance of water. The patient's explanatory models of arthritis influenced their psychosocial effects and coping mechanisms used. The authors concluded that it is important to understand culturally influenced perceptions of disease to successfully treat chronic disease.

Holt (2000) explored the concept of hope within the Dominican culture from data gathered in a rural village in the Dominican Republic. A total of 45 people were interviewed, mostly in groups of two or more. The study was based on documentation of the effect of hope or hopelessness on health, and compared the meaning of the concept of hope between rural Dominicans and mainstream U.S. populations. The Dominican concept of hope emerged as "an essential but dynamic life force that grows out of faith in God, is supported by relationships, resources and work, and results in 
the energy necessary to work for a desired future. Hope gives meaning and happiness" (p. 1124). This study also begins to explore the universals and diversities of hope among cultures, and its diverse meanings and attributes which affect care patterns in various cultures. Holt concluded that hope is a universal concept that is culturally perceived and defined by specific populations, as she explored the concept within a rural area of the Dominican Republic, and compared it to other conceptual definitions from the literature.

Schumacher (2010) presented research findings that support the previously cited studies. Schumacher studied Dominicans in their rural homeland, seeking to describe their beliefs and practices related to health promotion and care. She interviewed 19 general and 10 key informant using Leininger's Culture Care Theory as a framework for the qualitative study to explore the meanings, beliefs and practices of care for rural Dominicans in the DR. Three main themes emerged from this study: family presence is essential for meaningful care experiences and care practices; respect and attention are central to the meaning of care and care practices; and, rural Dominicans value and use both generic (folk) and professional care practices (p. 97).

\section{Studies in the New York City Area}

A patient in the Nui et al. (2011) study described arthritis as "a test to see if I can continue fighting or not" (p. 5), and similar findings described the concept of "luchar" (to persevere) as a coping mechanism for dealing with adverse health conditions, specifically breast cancer. Florez et al. (2009) designed a study using a qualitative interview approach to give voice to the perceptions of Dominican 
immigrant women living in NYC regarding cancer screening detection and beliefs about survival. The 25 Dominican women, aged 40 or older, were recruited using snowball technique, and participated in one-to-one interviews lasting about 45 minutes in their own homes or the homes of relative and friends. This research explored the Dominican women's emic health belief system to determine if early action and religious faith served as empowerment tools to prevent and cope with illness, while it examined the extent that beliefs about fatalism characterized women's attitudes and practices about breast cancer, and sought to discover the cultural beliefs that supported women's proactive behaviors regarding cancer screening and early detection, and the Dominican women's views about survival. Participants expressed faith in God's intervention, but took responsibility for their own life outcomes via the cultural framework of "luchar" (to persevere) (p. 298). Luchar centers on the belief in one's ability to fight and defeat adversity as an active coping process (Florez et al., 2009). Women in this study saw themselves as proactive agents in their health care, thereby influencing their illness destiny. In this study, "en la lucha" refers to an ongoing process of persevering, dealing with, and fighting against adverse health and other events in which willpower and self-reliance to overcome hardships are expected. The study found that women's emic perspectives of health and disease were devoid of hopelessness and resignation inherent in the fatalism construct, and results indicated that positive views on breast cancer and screening are produced and maintained through a complex framework of inner will and external forces that allow both survival and death to be possible from breast cancer. Findings suggest complex 
strategies and beliefs regarding breast cancer and cancer screening that reflect resiliency rather than hopelessness. These ideas are further supported by the Holt study (2000) that explored the concept of hope within the Dominican culture from data gathered in a rural village in the Dominican Republic. Holt discovered that everyone had hope in some form, and that "some informants could not conceive of a person without hope, while for others, hopelessness was a theoretical possibility which they could not imagine ever being a reality" (p. 1121).

Shedlin's \& Shulman's (2004) research evaluated access to care by Latino immigrant populations in the New York area, using a qualitative approach. They conducted focus groups with persons living with AIDS (PLWAs), to explore the perceptions, beliefs, experiences and knowledge of HIV care issues. The 57 participants included men and women from Mexico, the Dominican Republic, and Central America, ranging in age from 19 to 61. Results included detailed information on cultural meanings of HIV/AIDS; experience of stigma and rejection; the value of family support; gendered health-seeking behavior; testing issues; and satisfaction with services. The findings described the profound cultural impact of HIV on patient's lives related to disclosure of HIV status. Decisions about who to tell were affected by the important cultural value of 'familismo' (importance of the family, family loyalty, and strength of family bonds), and the distress of real or anticipated isolation because of disclosing their HIV status to family members. This concept was illustrated by a study participant's statement: "For those of us who are infected, you don't know how important the family is for us; the family can help to cure without medicine even the 
most terrible physical pain" (p. 439). Substantiating the value of family in the Dominican culture, studies done by Schumacher (2010) and Holt (2000) both validate the importance of family and relationships for social support, caring and healing. Shedlin \& Shulman's findings suggest that it is critical to understand the environment from which these immigrants come and the impact of immigration in order to be effective in reaching and providing services to this population. "Poverty, repressive governments, lack of education/literacy, ethnicity, class, color-based stigma and cultural norms are crucial factors in determining attitudes, motivations, decisions and behavior" (p. 434). The researchers recommend building on cultural norms and networking human and institutional resources as the most effective way to get clients to access and utilize available services.

Shedlin \& Shulman (2004) explain that people in rural areas of the Dominican Republic do not have access to professional health care, and therefore they are unfamiliar with this type of care and do not expect or seek it. This idea may be carried over to their health beliefs and practices in the United States, and migrant Dominicans may not understand or value preventative health care. In their country, with a magicoreligious belief system, the will of God, or supernatural forces of good and evil may have more to do with health care outcomes than other factors.

Several studies focus on generic (folk) Dominican practices related to the use of traditional medicine and healers in the Dominican Republic and New York City, and all of these indicate that adaptive changes in health practices occurred with migration, relative to the new environment. Allen et al. (2000) conducted a small pilot 
study of 50 primarily Dominican participants of low socioeconomic status in the emergency department (ED) of a large urban hospital in New York City, aiming to describe recent use of complementary and alternative medicine (CAM) by the study participants. In this study CAM is described as "medical interventions not taught widely in U.S. medical schools or generally available at U.S. hospitals" (p. 51) such as herbal remedies, acupuncture, homeopathy, massage, aromatherapy, meditation, reflexology, spiritual healing and prayer. As described here, CAM is conceptually equivalent to generic (folk) medicine, which was previously described as "care that is based on traditional, folk, lay, indigenous, local, home or alternative caring practices and skills that have been used by people, families and communities over time, and have been known and valued as first use, naturalistic, familiar, and beneficial healing skills and practices" (Leininger, 1997, p. 36). A convenience sample of 50 ED patients were interviewed to determine the nature of their presenting complaint and the use of CAM and conventional medicine, the perceived effectiveness of CAM treatments and conventional medicine used prior to coming to the $\mathrm{ED}$, and other use of these remedies in the past year. Potential subjects gave verbal consent to participate and were interviewed using a questionnaire. Interviewers were bilingual medical students in the ED and were introduced to potential respondents by the attending physician. Each interview lasted approximately ten to fifteen minutes. The sociodemographic characteristics of the sample were a mean age of 51 years, $68 \%$ female, and $82 \%$ Dominican. Five were born in the U.S., and most others were long-term residents with a mean of 19.2 years in the country. Eight percent mentioned that they 
practiced Santeria, and $40 \%$ had used some form of prayer to deal with a health problem. In general, the participants were poorly educated and economically disadvantaged. Half of the sample took conventional medicine for their presenting complaint and found it to be very to somewhat effective. Twenty-four percent of the group used CAM for their presenting complaint, and 28\% used CAM during the past year for a health problem. A vast majority used CAM in the form of an infused tea or drink for the most commonly reported presenting complaint of abdominal pain, and $25 \%$ found it "very" or "somewhat" effective. The most common self-made mixtures included tea from chamomile, anise, cinnamon, star anise, and linden flower. Eighty percent of those who used CAM in the past year reported it was "very" or "somewhat" effective in treating other health problems. CAM users were more likely to be female, longer-term residents of the U.S., who also used religious practices for health problems, such as high blood pressure, high blood sugar, colds, headaches, menstrual cramps, and everyday maintenance (p. 53). It is suggested that CAM is a less expensive way for Dominicans to treat health problems. The researchers conclude "traditions of using CAM remedies are not lost among Dominicans in New York City, as even long-term residents still use CAM. It is also possible that some patients are not satisfied with aspects of the U.S. health care system, thus increasing their reliance on traditional medicines" (Allen et al., 2000, p. 53).

Vandebroek et al. (2010) studied Dominican health practices, and documented the importance and complexity of plant mixtures (remedies consisting of at least two plants) in Dominican traditional medicine, and the variation in practices that was 
influenced by migration to NYC, where plants are readily available in NYC botanica shops and Latino grocery shops, but may differ from plants available in the DR. Participants were recruited from Washington Heights and the Bronx in New York City, and four provinces in the DR that matched the provinces where most participants originated from in the NYC study. Institutional Review Board approval for this study was granted by the City University of New York. Inclusion criteria for participants were a minimum age of 18 years, born in the DR, and self-reported familiarity with or knowledge of at least a few medicinal plants. After obtaining informed consent, a questionnaire was verbally administered in Spanish with the researcher asking questions and recording answers on the questionnaire form. The interview was also tape recorded. In total, 174 Dominicans were interviewed in NYC comprised of 165 lay persons who self-medicate with plants and 9 specialists in traditional healing. Participants consisted of 110 women and 64 men. 145 were interviewed in the DR (128 lay persons, 17 specialists, 87 women and 58 men). The interview questions were both quantitative and qualitative, with the main topic assessing knowledge of plants to treat 30 common health conditions. The health conditions were mentioned one at a time, and each participant was asked to name known medicinal plants, plant part used, preparation, mode of administration, and the location where the herbal remedy was used (NYC, DR, or both). The research found that respiratory conditions, reproductive health, and genitourinary conditions were the main categories for which Dominicans used plant mixtures. Lay persons reported significantly more mixtures prepared as teas, mainly used in NYC to treat respiratory conditions. Specialists used 
more botellas (bottled herbal mixtures), most frequently in the DR, to treat reproductive and genitourinary conditions. Interview participants also believed that plants used in combination mixtures increased their potency and versatility as medicines. Although this study focuses on ethnobotanical research, it validates the continued use of Dominican traditional medicine to treat health conditions by migrant Dominicans in the United States.

A study done by Ososki et al. (2002) focused on searching the literature on medicinal plants used in the DR to identify those used for women's conditions such as uterine fibroids, menorrhagia, endometriosis, and menopausal hot flashes. The research also compared the use of herbal treatments reported in the literature with those prescribed by Dominican healers in NYC, and evaluated the extent to which healers may have changed their use of plants in order to adapt to availability in the NYC environment. While 87 plant species were reported in the Dominican literature for these conditions and symptoms, only 19 species overlapped from the literature survey and the fieldwork with the six Dominican healers interviewed in NYC. This study documents changes in plant use as people migrate to urban centers where they are surrounded by diverse cultures, healing systems, and new environments, and encourages further investigation in this area (Ososki et al., p. 297).

Fugh-Berman et al. (2004) found that Dominican healers in NYC prescribe beets to treat uterine fibroids. The authors offer possible nutritional and cultural justification for using beets and molasses in Dominican ethnomedicine. First, endogenous estrogen levels could be reduced by the high dietary intake of fiber found 
in the beet root. Second, hormones, especially estrogen, affect the growth of fibroids, and may be found in beet leaves which appear to be estrogenic from studies done on cattle and mice. Third, the high carotenoids found in beets may inhibit the growth of fibroids. Of interest is the principle of "Doctrine of Signatures" where plants are thought to signal their uses through their appearance or behavior as in "like cures like" (Bellamy \& Pfister as cited in Fugh-Berman et al., 2004, p. 337). Beets and fibroids are similar in appearance and texture. Each exhibits a similar whorled pattern in cross-section, and is firm to the touch. Beets "bleed" when cut which may add to their gynecological significance among traditional healers. When beets are mixed with molasses, the potion may visually reinforce blood-building aspects of the remedy to treat symptoms of the fibroids, such as heavy menstrual bleeding. Both beets and molasses are recognized in folk medicine traditions to treat blood loss. One recommendation from this research is that beets may be a treatment for irondeficiency when combined with molasses due to the high iron content of both ingredients. Due to the high carotenoid content of beets, which is a precursor to Vitamin A, it is postulated that beets and molasses in combination may be a more effective way to treat iron-deficiency anemia and Vitamin A deficiency, than iron alone. The authors conclude that the ethno medical uses of plants by traditional cultures "is transplanted as cultures migrate to new areas, and may change as healers and their patients adapt to new settings, experiment with new species, and seek to maintain a semblance of their healing framework" (p. 338). 
These studies of Dominicans (Allen et al., 2000, Babbington et al., 1999; Florez et al., 2009; Fugh-Berman et al., 2004; Holt, 2000; Nui et al., 2011; Ososki et al., 2002; Schumacher, 2010; Shedlin \& Shulman, 2004; Vandebroek et al., 2010) illustrate the influence of cultural beliefs on Dominican health practices but a deeper understanding of the health-related beliefs, practices, and experiences of migrant Dominicans in the United States is needed.

\section{Gaps in the Literature}

The studies explore attitudes and beliefs about the etiology of disease or illness, traditional treatments, and supportive measures that Dominicans use for healing or restoring health, both in their native country and when they migrate to the New York City area. Of the studies done in the New York City area, Shedlin and Shulman (2004) reported that migrant Dominicans may be unfamiliar with the idea of professional health care in the United States, and therefore, may not expect or seek this type of care. In contrast, Schumacher (2010) reports that Dominicans living in rural areas of the DR value and use both generic (folk) and professional care practices. Vandebroek et al. (2010), Ososki et al. (2002), and Fugh-Berman et al. (2004) confirmed the use of medicinal plants prescribed by Dominican healers in New York City, and Ososki et al. documented changes in plant use as people migrate to urban centers where they are surrounded by diverse cultures, healing systems, and new environments. Allen et al. (2000) found CAM (generic folk care) users to be female, longer-term residents of the United States, who also used religious practices for health problems, and suggested that CAM is a less expensive way for migrant Dominicans to 
treat health problems. Supporting the relevance of this study, Allen et al. stated that "it is also possible that some patients are not satisfied with aspects of the U.S. health care system, thus increasing their reliance on traditional medicines" (p. 53). Specific practices used for maintaining health after migrating to the United States are still largely unknown to those outside the migrant Dominican community. While there is some literature that describes migrant Dominican health-related beliefs and practices in their new environment, there is no research that speaks of the migrant Dominican experience with professional health care in the United States from the Dominican perspective. This study will explore both the health-related beliefs and practices and the experience of health care for Dominicans in their new environment, building on the existing body of knowledge in the literature. In addition, this study will give voice to the Dominican perspective as the recipients of health care in the United States. 


\section{Chapter III}

\section{METHOD}

\section{Design of the Study}

The underpinning assumption of qualitative methodology is that individuals are valuable sources of information and are capable of expressing their own feelings and behaviors (Clarke, 1999). "Qualitative researchers want those who are studied to speak for themselves, to provide their perspectives in words and other actions" (Ely, 1991, p. 4). Therefore, a descriptive qualitative design is appropriate for answering the research question: What are the health-related beliefs, practices, and experiences of migrant Dominicans in the Northeastern United States?

Interpreter-facilitated opportunities to speak about their health-related beliefs, practices, and experiences can be the most comfortable way for migrant Dominicans to share information (Morgan, 1997). Therefore, participants were invited to share their beliefs, practices and experiences in focus groups.

Phillips, Luna de Hernandez and Torres de Ardon (as cited in Jones and Boyle, 2011), note that "credible, sensitive cross-cultural research cannot be done without collaboration with members of the culture who are equal partners on the research team" (p. 111). Subsequently, it became especially important to use culturally appropriate interpreters who were trusted by the migrant Dominicans to assist with recruitment and data collection. 


\section{Gaining Access and Establishing Rapport}

The effect of the researcher being culturally and linguistically different from the Dominicans was modified by the involvement of the interpreters who had worked closely with Dominicans (Jentsch, 1998). Unexpectedly, as I established rapport with three bilingual community leaders who were also interpreters for the present study, they became gatekeepers to the Dominican community, and helped me to gain access to potential participants for this study. I was an outsider in this group of Spanishspeaking migrant Dominicans, and I did not have the opportunity to have day to day community interaction that leads to becoming a trusted friend of the Dominicans. Therefore, the culturally appropriate bilingual interpreters, especially one who lived in the same building with most of the participants, played an essential role in promoting participation by enhancing the credibility of the research team and providing information about cultural sensitivities to the researcher (Halcomb, Ghlizadeh, DiGiacomo, Phillips \& Davidson, 2007).

The gatekeepers. Three interpreters played significant multiple roles in the present study. All had worked closely with the Dominican community, and all were interested in the research process because they were graduate students or had graduate degrees in nursing. They were known as community leaders among the Dominicans, and became gatekeepers that assisted me in building trust with the participants. One was a nurse colleague who was formerly the director of the Catholic Charities health clinic in the community before it was closed. She was well known to the leaders in the Latino Community in the city because of her work with the clinic and within the 
community. She perceived that trust was established between the clinic and the community based on the history of attendance and return visits by community members to the clinic. Some of the participants remembered her, and they were glad to see her present as an interpreter for the first focus group. The second interpreter was a nurse colleague who lived in the same building with many of the participants, and they knew her socially prior to the study. She allowed the groups to meet in her apartment in the building, which was safe, convenient, familiar, and comfortable for the participants. She was present to assist with all three of the focus groups. The third interpreter was a nurse colleague, who is a native Dominican, and migrated to the United States when she was eighteen years old. She is very familiar with the culture and ways of native Dominicans, and empathetic to the experience of migration from the Dominican Republic to this area of the United States. She was present to assist with the second and third focus groups.

The trusting relationship that I sought to develop with migrant Dominican participants developed quickly during the first focus group, and was supported by my introduction from these community gatekeepers/interpreters, and facilitated honest, credible, and in-depth data from participants (Leininger \& McFarland, 2002). It also laid the groundwork for establishing relationships and trust with other members of the community who would eventually participate in the study.

Building rapport. By the time I became an active participant in the focus group, the participants were relaxed and some rapport was established between the interpreters, the researcher, and the group due to previous encounters and 
introductions. Observing the Latina values of personalismo (personal engagement) through platica (small talk), I began the interview with a social conversation, demonstrating respect by acknowledging the participants and their families, and letting the participants know that I was interested in them in a personal way, not just as research study participants (Ojeda, Flores, Meza, and Morales, 2011). These initial interactions influenced the participants' perceptions of me, and contributed to the participants' comfort level, rapport between us, and confianza (trust). They kissed me hello and goodbye, and they personally thanked me for taking an interest in Dominicans and trying to make things better for them with my research.

\section{Working with Interpreters and Translators}

Selection. I needed interpreters and translators for this study because it was expected that the focus group interviews might become a mix of two languages. I had some formal education and familiarity with Spanish language, but I do not speak Spanish fluently. Therefore, three interpreters who were fluent in both English and Spanish were carefully selected to meet the criteria of being an expert in Dominican culture and language. They were considered to be culturally appropriate by nature of being a native Dominican or working closely with the Dominican community. Two of them were always present with the focus groups, and assisted with the interviews to clarify communication.

The bilingual people who assisted in this study acted as both interpreters and translators. To further explain this difference, interpreters listen to a spoken language and change it into the spoken form of another language, while translators change 
written text into another language in written form, or may read the text and translate it into another language orally (Jones \& Boyle, 2011, p. 110). According to Jones and Boyle, the quality of any translation is dependent on the cultural knowledge and linguistic skills of the bilingual person taking communication from one language to another, and this person is a key participant in the translation process.

Preparation. Congruent with this point of view, all of the interpreters and translators had training specific to the objectives of the study, and each interpreter had a completion certificate from the web-based NIH training program, "Protecting Human Research Participants.” In addition, all were advised of the confidentiality of the information obtained in the interviews, and signed a confidentiality agreement (see Appendix B) before the interviews began.

Guided by Jones and Boyle (2011), I planned adequate time for mutual teaching between the researcher and the interpreters and translators. I prepared them for the interviews by discussing qualitative research methods, the purpose and background of the study, interactive qualitative interviewing techniques, and ethical procedures, including informed consent and confidentiality. I taught the interpreters and translators about the research methods, and guidelines and rationale for the steps in the translation process, while the interpreters and translators taught me about the cultural values and social structures of the participant group. We had consensus on a plan that maintained scientific rigor while ensuring cultural sensitivity.

According to Williamson, Choi, Charcuk, Rempel, Pitre, Breitkreuz, and Kushner (2011), the primary goal of the interpreter role in communicating participant 
responses, was to achieve conceptual equivalence to the central meaning, while “remaining as close as possible to participants' words and being mindful not to embellish some points and/or omit others that are perceived by the interpreter to be unimportant, irrelevant, or inappropriate" (p. 384). Ascertaining the central meaning (conceptual equivalence) of interview questions and the participant responses, was deemed more important than producing verbatim translations. An outcome from teaching the interpreters about the objectives of the research involved a discussion about seeking care in the clinic versus care in the hospital. As the discussion progressed, the Dominican interpreter introduced and clarified their experience of the clinic and hospital being opposite in the Dominican Republic, compared to the United States. The clinic is the place where one pays privately, and it is staffed by private doctors. The hospital is the place where one can go for less money, and it is staffed by public employees. Therefore the care in a clinic is preferred if one can afford it in the Dominican Republic. This was validated by the participants. If this interpreter had not shared her knowledge and spoken up, I would have viewed the information that was presented in the opposite way, and perhaps misinterpreted the significance or meaning of the conversation.

Cultural brokers. After discussion and training, I trusted that the interpreter's cultural awareness led to interpreter translations which made the unscripted questions maximally acceptable to the participants, while the meaning of the original question was retained. The interpreters had an important role in evaluating the content of what was being translated and communicated. The interpreter's sensitivity and expertise 
helped with phrasing questions to elicit targeted information in a way that was culturally acceptable to the participants. They acted as cultural brokers, by evaluating or validating the researcher's perceptions about the conversations and group dynamics that occurred during the focus group sessions. The interpreters were cultural insiders with this group, and they were able to help me to more fully understand the meaning of what happened in each focus group.

\section{The Participants}

Eligibility. In order to meet the stated objectives of the research, participants met the following eligibility criteria:

1. Self-identified as a person from the Dominican Republic living in the United States for at least six months.

2. Willingness to share information and knowledge of Dominican beliefs, practices and experiences related to health promotion and treatment of illness.

3. Agreed to participate in two or three focus group interviews conducted by the researcher lasting up to two hours each time.

4. The informant/participant was 18 years of age or older.

Recruitment. The interpreters had many roles, and one of them also acted as an outreach worker to recruit participants for the study. A convenience sample of participants was recruited with the help of this bilingual outreach worker at a senior apartment building in this Dominican neighborhood, and from the surrounding migrant Dominican community using snowball technique. The outreach worker, who was also a nurse, lived in the same building, which facilitated recruitment efforts, and 
made her a trusted member of the community. For consistency in providing information, she used a script to inform the participants of the planned research about Dominican culture and their health beliefs and practices, and their experiences with doctors, nurses, and hospitals (professional health care) in the United States (see Appendix C). The literature recommended a group size between four and twelve participants, with the optimal size between five and ten individuals (Halcomb et al., 2007; Krueger \& Casey, 2009; Morgan, 1997), however, the pre-determined target for these groups to be successful with interpreters, was four to six participants per group. Using the recommendation of Halcomb et al, who reported that up to $20 \%$ of participants may fail to attend the focus group session, more participants than were required for the group were invited.

Those who had interest in participating were told the time and place to meet the researcher. In addition, flyers were distributed in the community with information about the study, but in the end, all of those who chose to participate were recruited by word of mouth.

All documents that were read to or by participants were translated by a culturally appropriate bilingual translator, and back translated into English by a native Dominican speaker for accuracy of meaning. The Dominican Spanish version of all written documents was used to communicate with the study participants.

Demographic survey. A demographic survey was used to collect descriptive data about the participant population. Demographic information included the length of time in the United States, primary language spoken, age, ability to read, ability to 
write, level of education, income, occupational status, and residence (see Appendix D). It was important for building trust and gaining participation, to design questions in such a way that the participants would never feel that the researcher was soliciting information about their immigration status. Specifically, questions about health insurance were not asked for this reason, but other questions were able to give the researcher indirect information about socio-economic status.

\section{Setting}

This study took place in the city where the participants were recruited, which is well-known as a predominately Hispanic community. According to statistics from the U. S. Census Bureau (2012), Hispanics or Latinos comprise $78.7 \%$ of the population of this city. Looking more closely at the reported demographics of the population, $29.2 \%$ were Puerto Rican, $9.5 \%$ were Mexican, $2.3 \%$ were Cuban, and $37.7 \%$ were of other Latino or Hispanic heritage, including Dominican. Within the community as a whole, $25.5 \%$ of the residents speak English at home, while $70.1 \%$ of residents speak Spanish at home. Of the group that speaks Spanish at home, 53\% speak English very well, while $47 \%$ speak English less than very well. Among foreign born English speakers, $6.2 \%$ speak English at home, while 86.2\% speak Spanish at home. Of the foreign born English speakers, 29\% speak English very well, and 71\% speak English less than very well (City-data.com, 2015). There was evidence of generic care in the community, as I observed many shops, or botanicas, that specialized in herbs, alternative medicine, and spiritual items. The supermarkets were also dedicated to typically Latino grocery items. 
The focus groups met in the building where many of the participants lived. The person who recruited the participants allowed us to use her apartment, so I believe the women felt safe and comfortable here, and trust was already established because they knew the recruiter and had developed a social relationship with her prior to the meetings. Each group met on a Sunday afternoon, and was assisted by two bilingual interpreters, who also acted as cultural brokers.

\section{Ethical Considerations}

Approval for this research was granted from the Institutional Review Board of Seton Hall University prior to the start of this study (Appendix E). In addition to required topics for the informed consent, there were some additional ethical issues that required consideration in the study design. I had to consider the vulnerability of the participants due to unknown immigration status, identity protection, accurate communication due to cultural and linguistic differences and literacy level, and providing a meeting place that was safe, comfortable and easily accessible for the participants.

According to the principles of respect, justice, and beneficence, the identity of the informants and the information revealed to the researcher was protected. Some participants may have been undocumented immigrants, and may have been reluctant to sign written consents because of potential legal ramifications if their identity was revealed. No participant was asked to reveal their immigration status at any time during the study or the consent process. Under circumstances that the research presented no more than minimal risk of harm to subjects and involved no procedures 
for which written consent was normally required outside of the research context, the witnessed mark of the participant served as the signed consent form for all of the subjects (U.S. Department of Health and Human Services, 2010a, 2010b). If the potential participants met the inclusion criteria, made a witnessed mark on the consent form, and returned a completed demographic survey before the focus groups began, they were included in the study. Since the education and literacy levels of the participants were varied, a verbal presentation in Spanish of the consent form and the demographic survey eliminated any doubt about the participant's comprehension or reading ability to complete the forms. The informed consent and the demographic survey were assigned matching numerical codes for each participant.

The participants were told that the study was voluntary, and that the group discussion would be audio-recorded. Participants were assured that the findings would not identify individual participants with their responses. If participants revealed themselves in the audio-recorded focus groups, the transcripts were changed to protect the identity of the participants. In addition, participants were told that their names would never be used in either the recording of field notes or in the write-up of the research findings. The participants were advised that if they felt any discomfort from the questions raised in the focus groups or the way they were treated in the group, they could refuse to answer the questions. They were told that they could stop participating in the study at any time, that they could withdraw from the study at any time, and that they could refuse to participate without any consequence to them. All the participants chose to remain in the study from beginning to end (Appendix G). 
Participants were told the research objectives and expected duration of participation, procedures, benefits and risks of participation, and the person to contact for questions about the research and participants' rights. The requirements to participate in this study were fully explained to the participants, and they were told that no risks or benefits for them individually were expected in this study. All participants in the study were given a written copy of the terms of participation in Spanish before the focus groups began (Appendix F).

The informed consent and the demographic survey were assigned matching numbers so that the participants did not have to reveal their names to the researcher. In order to get informants to participate in two or three focus groups to collect data and clarify perceptions of what was said, the informants were given an incentive to participate with the promise of a twenty-five dollar gift card, which they received after attending the final focus group. The participants gave their assigned number and contact information only to the bilingual interpreter, who could contact them if necessary, to give them information about the meeting times for the study, and to give them the twenty-five dollar gift card at the conclusion of the study.

The field notes, audio- recordings, and transcribed text were stored in the researcher's home in a locked cabinet. No one but the researcher has access to this locked cabinet.

\section{Data Collection}

Composition of the focus groups. Three focus groups met for about two hours at a time, for one or two sessions, over a period of three months. Several of the 
participants were part of more than one group, but the total number of participants was fifteen Dominicans. Ideally, four to six people were expected for the first group, but eventually thirteen women showed up to participate in the initial group. I did not want to separate these women, or turn any away, so the first focus group was very large, with all thirteen women participating in the discussion. This discussion was conducted in Spanish, according to the preference of the participants. In each of the three focus groups, the researcher acted as moderator, assisted by two culturally appropriate interpreters.

The second group was conducted in English, according to the preference of the participants, but consisted of only two people, a woman in her early sixties and a young man in his early twenties. The group included a migrant Dominican interpreter who aided with the discussion, and was present for the second and third focus groups.

The third focus group consisted of five women from the first group who were available to participate in this group, and it was conducted in Spanish, according to the preference of the participants. A participant in this group was bilingual and often acted as an interpreter by speaking to me in English, and then interpreting what she said into Spanish to share with the rest of the group. Unofficially, she often assumed the role of spokesperson for the group.

The number and mix of migrant Dominicans who consented to participate in the study dictated the composition of the focus groups, but the following information proved useful in observation and analysis of the data collected, and guided restructuring of the composition of the focus groups in subsequent interviews. 
Holcomb et al. (2007) recommended homogeneous focus groups to reduce the effect of power relationships and promote the comfort of participants, especially related to gender and age. Holcomb et al. suggested that it may be considered rude for younger persons to even suggest that they have opinions which differ from that of an older person, or one that is considered more senior or important, and to a lesser, but still significant extent, the same occurs with females in a group of males. An exclusively female group avoids the possibility of gender-related power relationships within the focus group. In an HIV needs assessment study conducted by Shedlin and Shulman (2004) with Dominican, Mexican and Central American immigrant groups in New York City, gendered health seeking behavior was identified in these groups. "The groups perceived that it was 'rare' that a Latino immigrant man would ask for information. Women were perceived as more likely to seek information, and men more likely to get correct information from spouses/partners than other ways." (Shedlin \& Shulman, p. 439). I specifically asked the participants if they were comfortable talking about health care issues with a mixed group of men and women, and the focus groups were set up accordingly. Only one young man participated in the group with another older woman, and I was alert to the patterns of communication and the potential influence of gender and age on the dynamics of that group. The other two groups were exclusively female, because they were the ones who showed up to participate in the study.

Procedure. Questions were prepared to guide the focus groups, and enhanced the consistency of data obtained between groups. Appendix A provides examples of 
inquiry statements that were used to explore Dominican beliefs, practices and experiences related to health in this group while living in the United States. Holcomb et al. (2007) suggested special considerations for participants from culturally and linguistically diverse backgrounds using structured questions, as opposed to openended questions. According to the literature, questions that were too open ended failed to yield answers sufficiently detailed to be meaningful. Providing concrete statements followed by shorter questions yielded greater data. This suggestion was useful in restructuring some of the questions from the original inquiry guide. It was determined that the questions "When do you consider yourself healthy?" and "What do you do to keep yourself healthy?" were better understood in translation if they were more direct, asking instead, "What practices do you use to stay healthy?" The first questions elicited vague responses, and questions about the question. The more direct question elicited more focused responses related to the topic of interest.

The focus groups were conducted according to an approach described by Williamson et al. (2011). As the researcher, I led the focus groups, which were conducted in Spanish by one interpreter, and then the responses were verbally summarized in English to me by a second bilingual interpreter, as each question was answered. This helped me with comprehension of the ongoing dialogue and allowed for a more natural flow of conversation, with minimal interruptions for translation. Each focus group interview was audio-recorded. The audio-recorded Spanish versions were saved as digital files, to preserve the content of the each focus group. Only the English summaries were transcribed to reflect the contextual conceptual equivalence 
of meaning from Dominican Spanish language. A second bilingual interpreter reviewed the English transcripts and the Spanish recordings, and compared the Spanish recordings to the English transcripts for consensus about the accuracy of the translation for the conceptual equivalence of meaning. The second interpreter/reviewer wrote memos in the margins to clarify or enhance the meaning in the English summaries. According to the interpreters who read the English transcripts while listening to the Spanish recordings, there was accurate translation in the transcripts, and very little difference in contextually equivalent meaning. This method gave validity to the translation by culturally appropriate translators, and reassured me that the meaning of our conversations had been captured accurately to give voice to these migrant Dominican participants.

Williamson et al. (2011) describe the procedure outlined above as an effective alternative to more commonly used and more laborious and expensive translation practices. This method generates valid data and is "less laborious and less costly than common translation practices and therefore should be considered as a viable alternative to full-translation interviews" (p. 390). There is an added benefit that the interpreters also help to explain and validate the researcher's feeling about the nonverbal communication that can only be observed by those present within the groups.

\section{Data Analysis}

Data from all focus groups was transcribed in the contextual English equivalent of the Spanish conversations. Recording the Spanish and English interviews allowed me to "present the interview" to the same or different translators, 
and to double check the translations (Jentsch, 1998).The transcribed data and observations noted in field journals, were reviewed at each phase of analysis. The transcripts were reviewed using content analysis and theme analysis. Participant's responses were analyzed with guidance from Leininger's four Phases of Ethnographic and Ethnonursing Data Analysis (Leininger, 2001) and recommendations from Ely (1991). The four phases that guided systematic analysis of the data are illustrated in Table 2.

First phase: Collecting, describing, and documenting raw data. During the first phase of analysis, I collected data and documented the data using a field journal, audio-recorder, and transcripts from the audio-recorded Spanish version of data that had been translated and transcribed into the contextual equivalent in English. A second translator compared the Spanish audio recording of the focus groups with the transcribed English contextual equivalent for accuracy of translation. Timely recording of observations and scheduled analytic memos at regular intervals in the process helped to keep me fair and honest by using recent memory for accurate recording. Immediate recording of interview/observation assured more accurate recall of the event. The major sources of data that I collected in the first phase were participant data from demographic surveys and focus groups, observationparticipation-reflection experiences, and my own thoughts and theoretical speculations and data from my written reflections from the field.

I kept a $\log$ that described my own responses to the interviews, theoretical speculations, feelings, and detailed observations of the participant's non-verbal 
behavior in context. Each field of data was dated, numbered, and given a focus group code. This allowed me, as the researcher, the possibility of going back to the original field notes and checking the data. I also held de-briefing sessions with the interpreters immediately following each focus group session to explore their observations of the group dynamics, non-verbal behaviors, and for feedback about the dialog to validate my observations.

As I reflected on each session, I considered the feedback and input from the interpreters. I made field notes about observations and thoughts during and after each interview to add to the data collection. This occurred immediately following each session as a post-session debriefing, while the content was vivid in memory. At this time, the interpreters and I also discussed ways to improve the next session. Some questions were reworded to generate more discussion or further explore specific topics. Other improvements were related to group dynamics and isolating smaller groups for more in-depth discussion. I looked for contextual meanings in the data, making preliminary interpretations, and recording data related to the phenomenon of interest obtained from an emic perspective. I remained attentive to etic ideas, including notes from discussions with the Dominican interpreters immediately following each focus group interview (Leininger, 2001).

\section{Second phase: Identification and categorizing of descriptors and}

components. In the second phase, each answer to the focus group questions was reviewed for common words, phrases, themes, and contexts. I coded the data and put it into categories related to the phenomenon of interest and the research questions. I 
examined beliefs and practices to promote health and to treat illness, as well as experiences with professional health care in the United States. Data descriptors were identified from the field data and studied within context for similarities and differences. There were similarities and differences between life in the Dominican Republic and life in the United States. I studied recurrent components for their meanings (Leininger, 2001).

Third phase: Pattern and contextual analysis. In the third phase, recurrent patterns were identified from the descriptors while retaining their contextual meaning. Data were examined "to discover saturation of ideas and recurrent patterns of similar and different meanings, expressions, structural forms, interpretations, or explanations of data related to the [phenomenon of interest]" (Leininger, 2001, p. 95). It was determined that sufficient focus groups had been conducted when data saturation was achieved with the three groups, because no new information emerged from the discussions, and there was redundant information amongst groups (Halcomb et al., 2007).

The guidelines for substantiation of the research were frequently reviewed and the data were processed accordingly for confirmability and credibility (Leininger, 2001, p. 95). Validation was ongoing regarding the researcher's interpretation of the observations with the participants for accuracy as data collection and analytic memos progressed throughout the observation period and when the findings were summarized at the end of the study. 


\section{Fourth phase: Major themes, research findings, theoretical formulations,}

and recommendations. In the fourth phase, themes were developed and abstracted from the patterns and analyzed for their congruence with findings from the literature. It required "synthesis of thinking, configurations, analysis, interpreting findings, and creative formulations from data of previous phases" (Leininger, 2001, p. 95). Research findings and recommendations emerged in this phase.

\section{Controlling Bias}

Throughout this study, I remained alert to the ways that my own bias could affect my interpretation of the data. Awareness is what kept my bias in check to present an accurate voice for the population that I studied. There was also the possibility that bias could be introduced by interpreters who assisted with the focus groups.

According to Leininger (2001), "[the ethnonursing method requires that] the researcher's biases, prejudices, opinions, and pre-professional interpretations [must]be withheld, suspended, or controlled so that informants can present their emic ideas and interpretations rather than those of the researcher" (p. 86). Learning to respect the people's views and experiences is an important skill. "Being cognizant of the researcher's views and any prejudices requires centering on the informant, active listening, and self-reflection, often with a research mentor. Avoiding a reinterpretation of the informant's ideas to fit professional knowledge and expectations is important" (Leininger, 2001, p. 87). 
I remained alert to the cultural context of the Dominicans which may have been enhanced by my knowledge of and experience in the bateyes of their native Dominican Republic. This is a possible bias that I kept in check, because not all Dominicans come from the socio-economic or educational background of the people I encountered as a participant in the service leadership mission while bringing professional health care to people in the rural areas of the Dominican Republic.

The background characteristics of the interpreters and the participants could have had effects on the data collection. I was able to inquire about the personal perceptions of the native Dominican interpreter, who was an insider to Dominican society, and her thoughts on specific responses given to particular questions, explicating the cultural context of the study. If data were difficult to understand, I asked the interpreter or the participants directly if a certain viewpoint was considered common, or a certain state of affairs was ordinary or unusual in the Dominican Republic (Jentsch, 1998). The interpreters were surprised at the "taboo topics" that were brought up in the focus group discussions such as the use of voodoo ("Everyone knows about it, but it is not discussed.") and candor about mental health issues and seeking counseling ("There is stigma associated with this, and it is not admitted or discussed.") The interpreters felt that there was a great deal of comfort and trust among the participants when they revealed these topics in the focus groups. Using a native bilingual interpreter provided a standard of language and cultural insight and understanding that could not have been obtained with an interpreter from outside Dominican culture. The bias was controlled to some degree by "the skilled observer 
from outside" (the researcher), and the "interpreter-insider" perspective (Jentsch, 1998).

\section{Establishing and Maintaining Trustworthiness}

Trustworthiness and being fair and honest in research has far reaching implications for the researcher, the participant population, and the evolving body of research knowledge about health-related beliefs, practices, and experiences of Dominicans living in the United States. I held myself accountable to reporting the phenomenon studied fairly and honestly, as experienced by the participating Dominican population, to "give voice to what they know" in the research.

Trustworthiness was maintained during this study using the criteria of credibility, transferability, dependability and confirmability (Lincoln \& Guba, 1985). Leininger added meaning-in-context and recurrent patterning as criteria for evaluating quality and rigor in culture care discoveries (Leininger \& McFarland, 2006, p. 23). I used these recommendations in establishing and maintaining the trustworthiness of this research.

To keep me fair and honest, I made use of my dissertation committee members and interpreters acting as cultural brokers, as a support group for feedback and new insight about the data collection and analysis. Feedback from colleagues facilitated more probing questions about the study by raising questions and new ideas that came from multiple perspectives. The group also held me accountable for bias in interpretation. In addition, nurse colleagues who assisted with transcription and interpretation, and members of this dissertation committee, who are experienced in 
qualitative research and culture, assisted me with review of the transcripts to establish inter-rater reliability. I used peer de-briefing to obtain feedback about the data quality and interpretive issues from the nurse colleagues who were bilingual interpreters for this study. The collaborative development of categories, with experienced colleagues to support data analysis decisions, increased the credibility of the findings.

As further measure of credibility, saturation was noted when there was a redundancy of the same or similar information, and data collection continued until the participants did not produce any new information in the focus groups. The themes extracted from the data analysis reflect saturation with every topic except the use of voodoo, and this is because many participants were unwilling to discuss the topic with me.

Validity was determined by member checks or summarizing the discussion of common themes for review and comment by the actual participants. This technique gave me feedback about the accuracy of the analysis and allowed for further input. I confirmed ongoing interpretations with participants in order to obtain credible data. In the final validating step I determined how my findings compared with their experiences, from their point of view. For example, when I told the participants that I was already aware of certain practices, such as voodoo, because it had been revealed to me, then it gave them the opportunity to expand on this practice. In this case, there was a very mixed response. Some acknowledged that it existed, some said it did not, and others were so uncomfortable that they got up and left the group discussion. 
The findings of this study are presented with rich descriptions of demographic characteristics, and rich, thick descriptions of themes from the data collection and analysis, so that findings with similar meanings and relevance may be transferrable to research findings in a similar situation or context.

I noted recurrent patterning, or dependability, from repeated experiences, expressions, or accounts of events or activities that reflected sequenced patterns of behavior or repetitive topic discussion in the focus groups, and I remained alert to recurrent patterns in individuals and among participants while analyzing the data. For example, the first use of plant based home remedies and medicinal teas to promote healing and maintain health, and the detrimental effect of stress on health were recurrent threads throughout every discussion in the focus groups.

I maintained detailed and accurate records throughout the research process to serve as a method of establishing confirmability and creating an audit trail to identify analytical decisions made during data collection and analysis. Audio-recordings and field notes are available for review to confirm the findings of the research. My reflective notes on the data collected, including notes about discussions with interpreters and participants to clarify or confirm my interpretation of the findings, also document the research process. Checking data obtained by a variety of methods is one way of contributing trustworthiness. According to Ely (1991), experts agree that triangulation characteristically depends on the convergence of data gathered by different methods, such as observation and interview, which were used in this study. My formal knowledge and experience with the culture, enhanced by carefully 
selected bilingual and culturally appropriate interpreters, facilitated finding meaningin-context. I used a culturally appropriate bilingual translator to listen to the audiorecorded focus group interviews in Spanish and to review the transcripts and recordings of the interpreter's English summaries of conceptual equivalence for the focus group interviews. This second translator wrote comments or memos about the English summaries to validate the accuracy of the conceptual equivalence provided by the first translator, and the researcher considered both perspectives in the data collection and analysis. Accurate translation using the methods described did not change the meaning of what was reported in Spanish. Interviewing the participants in their familiar environment was helpful in finding meaning-in-context for what was reported. 


\section{Chapter IV}

\section{FINDINGS}

\section{The Participants}

Fifteen people who met the inclusion criteria consented to participate in the study. Table 1 illustrates a demographic snapshot of the participants. The characteristics of the convenience sample varied widely in age, education, household income, and the amount of time they have lived outside of their native Dominican Republic, yet all shared similar health beliefs and practices. 


\section{Table 1}

Demographic Snapshot of the Participants

\begin{tabular}{|c|c|c|c|c|c|c|c|c|c|c|c|c|c|c|}
\hline ID\# & Sex & Age & $\begin{array}{l}\text { Lived in } \\
\text { DR/years }\end{array}$ & $\begin{array}{l}\text { Lived in } \\
\text { US/years }\end{array}$ & Married & $\begin{array}{c}\text { Education } \\
\text { in years }\end{array}$ & \begin{tabular}{|c|} 
Read \\
English
\end{tabular} & $\begin{array}{c}\text { Write } \\
\text { English }\end{array}$ & Work in DR & Work in US & $\begin{array}{c}\text { Own a } \\
\text { car }\end{array}$ & $\begin{array}{l}\text { People } \\
\text { in home }\end{array}$ & $\begin{array}{c}\text { \# Share bill } \\
\text { payment }\end{array}$ & $\begin{array}{l}\text { Household } \\
\text { Income }\end{array}$ \\
\hline 1010 & $F$ & 80 & 31 & 50 & & 2 & & & seamstress & & $x$ & 1 & 1 & 2 \\
\hline 1009 & $F$ & 78 & 35 & 43 & & 8 & & & model & housewife & & 8 & 3 & 3 \\
\hline 1005 & $F$ & 74 & 22 & 52 & & 6 & & & homemaker & retired & & 1 & 1 & 1 \\
\hline 1011 & $F$ & 72 & 50 & 20 & & 8 & & & housewife & factory worker & & 1 & 1 & 2 \\
\hline 1002 & $F$ & 61 & 30 & 31 & & 8 & & & & forkift operator & $x$ & 1 & 1 & 2 \\
\hline 1014 & $F$ & 61 & 9 & 52 & & 12 & $x$ & $x$ & child & home health aide/secretary & $x$ & 2 & 2 & 2 \\
\hline 1001 & $F$ & 60 & 40 & 20 & & 6 & & & & packaging & $x$ & 1 & 1 & 3 \\
\hline 1008 & $F$ & 60 & 50 & 10 & & 12 & & & beautician & beautician & & 4 & 2 & 2 \\
\hline 1007 & $F$ & 58 & 28 & 30 & & 7 & & & homemaker & disabled & & 1 & 1 & 1 \\
\hline 1003 & $F$ & 56 & 17 & 39 & & 11 & & & none & bus driver & $x$ & 1 & 1 & 2 \\
\hline 1006 & $F$ & 53 & 27 & 26 & & 12 & & & homemaker & factory worker/bus driver & & 3 & 1 & 6 \\
\hline 1012 & $F$ & 51 & 35 & 16 & $x$ & 12 & & & beautican & beautician & & 3 & 3 & 1 \\
\hline 1004 & $F$ & 50 & 37 & 13 & $x$ & 4 & & & homemaker & home care & $x$ & 3 & 3 & 5 \\
\hline 1013 & $F$ & 28 & 7 & 21 & & 16 & $x$ & $x$ & student & banking/self-em ploy & $x$ & 3 & 1 & 6 \\
\hline 1015 & $M$ & 23 & & & & 12 & $x$ & $x$ & car wash & electrician & $x$ & 5 & 1 & 1 \\
\hline
\end{tabular}

Key for Annual Household Income

$1=$ less than $\$ 10,000$

$2=\$ 10,001$ to $\$ 20,000$

$3=\$ 20,001$ to $\$ 30,000$

$4=\$ 30,001$ to $\$ 40,000$

$5=\$ 40,001$ to $\$ 50,000$

$6=$ more than $\$ 50,000$

Blank cells indicate that the participant did not answer these questions in the survey. 
Age and gender. Fourteen of the participants were female and one was male. They ranged in age from 23 years old to 80 years old, with a mean age of 58 and a median age of 60. The number of years that the participants lived in the Dominican Republic is equal to their age when they migrated to the United States, as all lived exclusively in the DR prior to migrating (See Table 1). Thirteen said a mixed gender group was acceptable for them to discuss topics related to health, and two females said no. This was easily accommodated as there was only one male who participated in one focus group.

Marital status and children. Two of the participants were married, and 13 were presently unmarried, but it is unknown if they were ever married because this question was not asked. Thirteen participants reported having children, one had no children, and one did not answer this question. The participants reported having as many as five children, with the average being two children. It was not asked if the participants lived together with their children at the present time.

Time in the U.S., language and literacy. The participants lived in the Dominican Republic from seven years to 50 years. Most had lived in the United States an average of twenty nine years, although the time varied from ten years to fifty-two years. All spoke Spanish at home, and all reported that they could read and write in Spanish. Those who were fluent in English came to the U.S. as children. Three could read and converse in English as well as Spanish. One participant was fluently bilingual in all forms of reading, writing and speaking. 
Education and employment. The range of education was from two years in school for the oldest woman (80 years old) to a college graduate with 16 years of formal school. Three finished high school, and one finished college. One participant was a self-employed business owner related to banking, and most of the others had been employed in blue collar jobs in factories, beauty salons, schools or hospitals. One participant was a bus driver, and one was a fork lift operator. Most of the participants reported being homemakers when they lived in the Dominican Republic. Two-thirds of the participants did not work outside of the home before they migrated, but most started outside employment once they came to the United States. Many of the women were retired now, and one was disabled due to medical problems and mental health issues.

Households and income. Members of the household ranged from one to eight people. Seven of the fifteen lived alone. Most participants paid their own household bills without help from the income of a partner or other family members. Four households had more than one person contributing income to pay the bills. The self-reported household income ranged from less than $\$ 10,000$ to more than $\$ 50,000$ with an average income of $\$ 20,000$ to $\$ 30,000$ annually. Eighty percent $(n=12)$ earn less than $\$ 30,000$ per household, one earns $\$ 40,000$ to $\$ 50,000$, and two households earn more than $\$ 50,000$ per year. Fifty-four percent $(n=8)$ of the fifteen participants owned a car. According to the Poverty Guidelines (U.S. Department of Health and Human Services, 2014), $47 \%$ of this sample are living in poverty, while $14 \%$ earn more than $\$ 50,000$ annually. In the illustration, the lowest number for household 
income correlates with the lowest reported annual household income (see key for Table 1).

The participants appeared to be a close knit group of women who have known each other for a very long time. Most of the women were older, between 50 and 80 years old, and most of them lived independently in the Senior Building where we met for the focus groups. They were all nicely dressed and well-groomed when they arrived to participate in the study, perhaps to make a favorable impression on behalf of their group, or to acknowledge the importance of the meeting.

\section{Results}

Data were analyzed using Leininger's four-phase method of analysis (Leininger, 2001, p. 95), as illustrated in Table 2. During the fourth phase, four major themes were identified from recurrent patterns in the data. Four themes were revealed: (a) stress affects health and well-being, (b) family support and faith in God are essential for healing, and promoting health and well-being, (c) migrant Dominicans use both folk care and professional care to treat illness and promote healing, health, and well-being, and (d) perceptions about the quality of care are affected by access to care, cost, communication, and expressions of caring practices. Although the migrant Dominican participants have lived in the United States for many years, much of their reference in conversation compared the way of life in the Dominican Republic to the way of life in the United States, and recurrent patterns and themes emerged from this comparison. 


\section{Table 2}

Findings Using Leininger's Phases of Ethnonursing Analysis for Qualitative Data

\begin{tabular}{|c|c|c|c|}
\hline $\begin{array}{l}\text { Phase 1; Collect, Describe } \\
\text { \& Document Raw Data }\end{array}$ & $\begin{array}{l}\text { Phase lli Identify Categories of } \\
\text { Descriptors from Raw Data }\end{array}$ & $\begin{array}{l}\text { Phase Illi Scrutinize Categories in Context for } \\
\text { Recurrent Patterns of Saturation }\end{array}$ & $\begin{array}{l}\text { Phare IV: Synthesize \& Interprat } \\
\text { Findings to Extracted Themes }\end{array}$ \\
\hline Interview data: $\rightarrow$ & Twelve Categories: $\rightarrow$ & RecurrentPatterns: $\rightarrow$ & Four Themes: \\
\hline $\begin{array}{l}\text { Exploration of } \\
\text { Health-related } \\
\text { beliefs, practices, and } \\
\text { experiences } \\
\text { through focus groups! } \\
\text { Cultural values, } \\
\text { beliefs, \& lifeways } \\
\text { Religious \& } \\
\text { Philosophical } \\
\text { Kinship\& } \\
\text { 5ocial } \\
\text { Economic } \\
\text { Educational } \\
\text { Environment }\end{array}$ & $\begin{array}{l}\text { Beliefs and practices to } \\
\text { promote health } \\
\text { Quality of food } \\
\text { Family support } \\
\text { Faith and religious } \\
\text { beliefs } \\
\text { Natural home remedies } \\
\text { Spiritualfmystical beliefs } \\
\text { and practices } \\
\text { Treatment of illness } \\
\text { Experiences with } \\
\text { Proferssional health care } \\
\text { Cost of profersional care } \\
\text { Communication } \\
\text { Non-caring practices } \\
\text { Dealing with quality of }\end{array}$ & $\begin{array}{l}\text { - Stress is related to U.5, lifestyle, work, and } \\
\text { environment } \\
\text { - Family is everything and their support can cure } \\
\text { without medicine } \\
\text { - Faith in God and prayers will bring solutions to } \\
\text { problems } \\
\text { - The priest is preferred for advice to cope with } \\
\text { stress } \\
\text { - Use folk medicine firstfrom plants and teas } \\
\text { - Use natural home remedies before prescription } \\
\text { drugs } \\
\text { - Doctors are for emergencies and to treat serious } \\
\text { illnesses } \\
\text { - Some use spiritual/mystical practices for healing } \\
\text { - Cost of professional care } \\
\text { - Lack of interpreters in medical offices makes } \\
\text { communication and trust difficult } \\
\text { - Expressions of caring practices include paying } \\
\text { attention, spending time and listening } \\
\text { - Not spending time with the client is perceived as } \\
\text { disrespectful and uncaring } \\
\text { - Dominicans use patient satigaction surveys to } \\
\text { woice concern with professional care }\end{array}$ & $\begin{array}{l}\text { - Stress affects health } \\
\text { \& well-being } \\
\text { - Family support \& taith in } \\
\text { God are essential for healing } \\
\text { and promoting health \& } \\
\text { well-being } \\
\text { - Migrant Dominicans use both } \\
\text { tolk care and professional care } \\
\text { to treatillness \& promote } \\
\text { healing health, and well-being } \\
\text { - Perceptions about the quality } \\
\text { of professional care are affected } \\
\text { by access to care, cost } \\
\text { communication, and } \\
\text { expressions of caring practices }\end{array}$ \\
\hline
\end{tabular}




\section{Themes}

\section{Theme One: Stress Affects Health and Well-Being Differences Between Life in the Dominican Republic and the United States}

There are many differences in lifestyle between the Dominican Republic and the United States, as the participants described it. The changes they described required them to continuously adapt to the new culture in the United States, and became a source of stress that negatively impacted their health and well-being. They identified differences such as weather, level of recreational activity outdoors, patterns of socialization, quality of food, and levels of stress related to time and work, lack of social support, change in lifestyle, caring for family, and the environment. Many of them have lived in the United States for more than thirty years, yet they were quick to remember their life in the Dominican Republic as if they had just left yesterday.

The participants felt that activity for pleasure was more common in the Dominican Republic, and included "walking in the park, breathing in fresh oxygen that purifies your lungs and your blood, and sharing time with family and friends where your mind is at another level (stress relief)." Life in the Dominican Republic was more laid back and relaxed.

The majority of the women had been homemakers in the Dominican, but they had to work outside the home when they came to the United States. They gave examples of how daily activity is different, and compared work activity to activity for pleasure. When they spoke about work activity, the focus was on what happened during a work day here. They felt they had to rush to get to work to punch a time 
clock because there is no excuse for being late, and described a lot of pressure and consequences if they were not on time. This different concept of time added more stress to their daily life here. By comparison, in the Dominican, "if we are going to arrive a little later than expected, we just call and say I'm going to get there around 10 instead of 9:30 and everyone says, that's okay, we will see you when you get here."

The participants spoke about lifestyle in the United States that leads to poor health because life here is much more sedentary. After a work day here, they shower at home and sit in front of the television to eat dinner. When the weather was warm all the time in the Dominican, they were able to go outside and walk more. Here, they don't go outside as much, and there isn't as much opportunity for exercise. One woman described it like this: "When I was in my country, I was used to walking in the park. I didn't maintain a diet per se, but I had a more regular and relaxed life. Here I must work sitting down, something I was not used to. Sitting is sedentary, in addition to closing our doors and being in-doors due to a long winter which is a big difference that we experience when we come here."

Another woman stated, “Here, you don't have help. You're working, you come back home and you're still working because you are cleaning, you are taking care of the kids, taking care of your spouse and you're stressed. You have a constant stress level, and you add that stress to your heart, your high blood pressure, and everything has to do with your nervous system and you start getting fibromyalgia, and you start getting all kinds of different things that leads to other problems! So, that's an important factor related to health that I think has a lot to do with the lifestyle." 
Another participant added, "The lifestyle over there is very different because we have help. You can afford to have a maid that can cook for you, that can clean for you and so you have more time to spend with your family and even if you are not eating right because the food we have culturally is very fattening and high in carbohydrates so it leads to diabetes and stuff like that. Your mental stress is not adding to that bad habit of not eating healthy, I think it just minimizes the time and the speed of how sick people get. Because my grandparents for instance, they lived up to 98 and 100, and barely got sick, and it wasn't like they were eating healthy but they had more activities because they had more help at the house."

The participants described a difference in the food and diet in the U.S., compared to food in the Dominican Republic, and felt that the quality of food was better in the Dominican Republic. Here there are not as many fresh fruits and vegetables, or things that they are used to eating in the Dominican. According to them, the foods here are more processed, and they have more chemical additives, and the food is not as healthy as the food in the Dominican. One woman said that she ate only fruit when she first came to the United States because everything else made her nauseous, and she lost a lot of weight initially. She described in this way: "The foods here, the majority of the foods are processed and have food coloring and lots of other things. So they don't have the same flavor and nutrients that the body needs. We do not have the same quality of life and the same nutrients that we have back in our county in comparison to the nutrients we consume here. However, we must eat, and so we eat what is available to us." 
Another woman added, "Even fresh food in the United States is treated with chemicals or antibiotics, or the soil is different for growing vegetables and herbs, so that they taste different, Food quality is better in the Dominican Republic." They said that if you try to eat natural or organic foods here, it tends to be much more expensive.

According to the participants, the way one consumes food also contributes to health, especially as stated by the eldest woman in the group. "Good eating habits include eating our meals at a consistent time every day, and exercising regularly, living a tranquil, peaceful life." She eats small portions, but eats rice and salad. Small portions are key. She says her friends tell her she doesn't eat enough, but she feels good eating little.

\section{Coping with Stress}

The participants expressed that being happy with their lives promoted good health, and identified stress as a big problem that affected how they functioned on a physical level. The participants said, "If you try to change your job, or do something less stressful, it will ultimately result in improved health." They valued mental tranquility as a pathway to good health.

One woman spoke on behalf of the group: "For me, staying healthy has to do with quality of life, which in turn deals with nutrition and diet, exercise, healthy foods/eating, good sleep habits, and feeling satisfaction of a good job. Quality of life has to do with all of those things mentioned to maintain good health. In addition, the financial or economic state of the person affects their health because it can lead to 
deterioration of mental health. Quality of life includes many things." "I believe that how one feels is determined by how one lives their life."

Participants shared their experience of seeking counseling to cope with stress in their lives, so that they can relax and be healthy. They saw mental health as a factor that contributes to physical health, and stress as a leading cause of deterioration of health. They all agreed that there is a definite mind and body connection that needs to be balanced for good health.

The group consensus was that one should try to stay away from stress, and they illustrated this in the following statements: "Stress will kill you." "People become sick from a lot of stress. With stress, the body can become weak and sick. There are people that are physically sick. For instance, they may have a heart condition, and then, there are people who are sick because of stress and depression. For me, my belief is that depression and stress can affect both the mind and the body, and it makes you sick."

They talked about causes of stress and avoiding stress, which may indicate that they have learned some coping strategies over time. They suggested that in a stressful situation, such as a fight with a family member, one could walk away from a fight, ride a bike, listen to music, take a walk, or go on the computer, but at times the computer adds to stress.

The participants spoke about other practices that reduce stress and contribute to good health. Keeping active and engaged with others was described as a way to stay healthy. One participant talked about "the second age," (perhaps middle age) where it 
is important to keep busy, go to clubs and be with people, "it keeps you happier with less stress." She then discussed "the third age, when one is in their 70's." "Sadness comes with age, sometimes with sickness, because of age. You feel limited to do certain things you used to be able to do, and you cannot anymore. There are clubs for the third age, and all are in the same boat with limitations."

Another woman stated that it helps to have a companion, like a cat or dog, "because it gives you an activity to walk them, and you don't feel as lonely." Some keep active by visiting nursing homes and volunteering there. They feel that giving back by helping the elderly is a way to feel good and keep positive. They spoke about church groups where the atmosphere is positive, and support groups with a positive focus. "We become victims of circumstance that make us fall deeper down. At the end of the day, this alters your emotional level and creates stress."

There was a discussion about positive thinking, and always having faith that things are going to come about. It was also explained that when you come to this country, you must adapt to a system of life that is totally different and the mode of thinking should be much more positive. "When you have a problem, and you remain positive in your thinking, these help you to grow and to strengthen your mental state of health."

The youngest and most educated female in the group, who was also fluent in Spanish and English, had many suggestions for the other women, and for Dominicans in general, to maintain a positive focus in life to reduce stress. She believed they should gear into educating themselves to think positively. She recommended book 
clubs in Spanish focused on empowering women, and using Google, the internet, and grandchildren to help them out. She said they should have an interest in community service, be more involved with the church, or start a support group for women who don't know how to use available tools like the internet, in the church. "Form a little group that meets once a month, and read about how much more options they have rather than just thinking in a box." She wants them to look at the healthier side, instead of focusing on things that don't have a solution. "This way we can open our minds, so our creativity is inspired to find solutions." She felt that the women should read books and educate themselves emotionally to better themselves. The ideas expressed by these Dominican women indicate a desire to work for solutions to reduce stress among themselves, and to improve the health of individuals and the community.

Theme Two: Family Support and Faith in God Are Essential for Healing and Promoting Health and Well-Being

\section{Family Support}

The participants agreed that "health begins with the love and support of family." They expressed their beliefs by saying things like "one of the strongest forces between us that we share as human beings is unity of family." The literature describes the common value of familismo, the importance of family, family loyalty, and strength of family bonds, in Hispanic culture (Siatkowski, 2007), and Dominican culture in particular (Holt, 2000; Schumacher, 2010; Shedlin \& Shulman, 2004). The participants described familismo with the following examples: 
"Family support and/or concern for our loved ones when they are in poor health affect our individual state of well-being."

"My treatment (for cancer) is the support and love that my family gives to me."

"It is not necessary for an individual to become ill (or to die) for us to care for a loved one or show support and love towards them, but we must do this before they reach a state of poor health. We show our love and support at all times, not just times of illness.”

Many of them told other stories that demonstrated the power of family in healing, and a desire to involve the family in care and important decisions.

They told me that they prefer to talk to someone of the same gender or within the family when the issue is related to their reproductive organs. There is a sense of privacy or "being personal," related to reproductive or "private parts." The male participant said that he would not talk to his parents about private parts. "If I have that problem I don't talk to nobody about it. I go to the doctors, yes. But I got a different problem, and then I talk to my father. (He lives with his father in the United States.) I have a friend, not a relationship to my father, but she is an older person, like a mother, she's my friend. And I can go to her and ask her something, if it's not really, really personal." I was told that females manage the health of the family, they know the recipes for home remedies, and they are the most reliable source for advice for a health problem before one sees the doctor. Again, the participants stressed the importance of family support as a part of the treatment and healing process. 
"We are hard-working people to better the family and help the ones who are back there, that's what we do." Family support and helping each other is recognized as a vital part of good health and healing, whether one is healthy or one is sick.

\section{Faith in God}

The participants agreed that having a relationship with God, and with the priest, and with the church, helps to protect health. They believe that God would never give them something that is harmful. "If you are going through an experience that is not good right now, health-wise, it must be because there is a purpose, a divine purpose of some sort. We accept it. And we go through it, with strength, and a positive train of thought. We have faith that God will put us through the right paths and help us get better, and we actually start contributing to being more healthy. We believe that God will give us health, and will look after us, therefore, we are just going to let things be, and help God by maintaining a healthy lifestyle, and eating right, doing the exercise and consulting the priest, and consulting the doctor, and have that faith." "When you have faith, it is one of the most important parts of healing in our culture."

\section{The Power of Prayer}

The participants spoke about a spiritual piece related to being healthy or being sick, and how the power of prayer can help one to get better. "Meditation is very good. Because you need to meditate in order to pray and have that peace. And have that time alone. You need that. And that's what helped me. And there are certain things that you repeat and then it helps. It doesn't have to be a prayer. It could be 
something that you want to do for yourself that it would be better. Like an affirmation."

A woman described her experience at a three day retreat session in the Bronx. She said there was a lot of praying, and "three days of concentration and reflection on your sadness, very spiritual and very good. I loved it a lot. I came back and I felt so liberated. To be able to explain it, and for someone to understand it, you have to live it."

One participant illustrated her practices with the following statement: "When I feel I cannot find solutions, I pray to God and say you can fix all. I tell God, I did all I could, and now I leave it to your hands. Help me fix it, or you just fix it for me. Everything has a solution; you just have to wait for it. When I am looking for a solution that I can't find, I will pray for it, and everything will come. A solution will come."

The participants discussed their personal experiences with near death, and told me that there is a lot of testimony from people who have had near death experiences, and all the separate experiences, and all the stories that they hear, that gives them more faith in God, and that makes them feel, like "You know what? If the worst would be death, and it's that way, then God knows exactly that this is the best thing for me." This faith helps them to battle through all kinds of circumstances, whether it's financial distress that would cause health problems, or stress and depression. Hearing those stories, or having those types of experiences, lets them know, "we're not at the end of the road, and we have to go through this pain of illness, or back pain, or heart 
surgery, they know how to be at that state of total tranquility, which is like an ecstasy type of feeling."

\section{Our Relationship with the Priest}

The participants talked about their relationship with the priest, and state that they prefer to talk to a priest about their problems, rather than a professional counselor. They describe the relationship in this way: "I think it is a reaffirmation of faith. When you believe that things are going to be okay, and you have a priest that you know, he is someone in our community that we look to as the symbol of everything that could be, that can make everything better. The creator of everything. It is like the reaffirmation, guidance; he is kind of like a counselor." One woman states "I got advice from the priest, and not with the professional, because everything with her was negative." Another participant shared "I am used to talking to a priest. If I am not happy with what he says, I find a new one. A new priest, and I tell him what I told the other priest, and that I didn't like the answers." When speaking to another priest, she will tell him, not the name of the first priest, but the conversation, and that she didn't like the answers. The women state that they "prefer a priest to a professional counselor because they have a better connection."

There is a lack of trust or relationship with a professional therapist. One of the participants stated, "I think that as a priest who is dedicated to give faith to people, and give them guidance, that's why they feel a stronger bond and relationship. And they say he's a good priest, and they feel comfortable. That's where the lack is. Sometimes professionals lack that personal sensitivity with people." 
Considering the statements from these participants, it is important to involve the family in care and decisions, and to incorporate faith-based strategies to promote healing and well-being in this Dominican community.

\section{Theme Three: Migrant Dominicans Use Both Folk Care and Professional Care to Treat Illness and Promote Healing, Health, and Well-Being}

The participants revealed that they use a combination of traditional folk medicine and professional care for treatment of illness. All of the participants used natural home remedies first to protect, maintain, and care for their health. If they did not feel well, and they could not find a cure with home remedies, then they might add prayers or seek the advice of healers that can cure illnesses brought on by spells or evil eye. Some participants were willing to discuss magico-religious beliefs and practices for healing, others said they knew about it but would not talk about it, and still others said they knew nothing about this and got up to leave the focus group discussion.

The participants did not rely exclusively on natural home remedies, and all used professional care at some time, but the use of home remedies sometimes contributed to the reasons they delayed seeking professional care earlier during their illness. If the home remedies did not work, they said they would go to a doctor, which is the same as what they would do if they were in the Dominican. Here, and in the Dominican, the doctor is used mostly for an emergency. They described chest pain as an example of an emergency. One woman had a cardiac catheterization, and had a myocardial infarction on the table. Another woman showed us her pacemaker site. Her 
pacemaker malfunctioned and she ended up back in the hospital. The participants described trusting their doctors because their doctors saved their lives.

The typical use of folk medicine and professional care concurrently is clearly illustrated in the example given by a participant who is being treated for asthma. She described juicing with oranges and cantaloupes to clear allergies and sinuses. She also likes the anti-inflammatory properties of honey, to help with airways, and uses a juice of green onion, spinach, watercress and radish for the throat and allergies. She says that she will continue to use the nebulizer in the morning and evening, but will try to replace it with things that are more healthy, "to stop my dependency on that." "In Dominican culture, we go to the doctor as a last resort. We believe in God and faith, and we call an aunt or grandmother for home remedies. If it doesn't work, we go to the doctor for a prescription. That's what they (Dominicans) do there, and when they come here...go to the Farmer's Market to find that remedy, or that herb, or the ingredients to do that remedy, and they have their little book of remedies and herbs that they put together."

\section{Natural Home Remedies}

While several participants believed in juicing to release toxins from food and stress, others spoke about using daily tea formulas to promote their health. "There is a tea for everything if my mother is around. Every night I drink tea because I like it. Ginger root, we cut it up and boil it, limes, we boil it, apples sometimes, and we boil it, cut up. I boil oregano every morning and I drink it." Most used recipes passed down from the older females in their families, like aunts, mothers, or grandmothers, 
and they also treated minor illnesses with teas. They used tea for things like digestion and stomach problems, constipation, nausea, diarrhea, chest congestion, and breathing problems.

The groups gave examples of some teas and remedies that are commonly used. "We make tea from the leaves on our patio." Orange leaves are good for the digestive system and vomiting. For an upset stomach, use lemon with salt, or more specifically, eight ounces of water, lemon, a bit of soda, a teaspoon of salt, mix well and drink it. Squeeze a lemon in hot water, it is good for an acid stomach, and it stops acid reflux. Warm filtered water and lemon is used for cleansing the stomach, as an aid to bowel elimination, and it kills bacteria. Yucca will cure diarrhea right away, or use wheat flour and red wine. "My mother uses oregano for my stomach, and vinegar. It is good for kids with diarrhea."

Boil chamomile tea and sweeten it with a teaspoon of honey and it relaxes you and it helps you sleep soundly. Honey, watercress, onion and radish opens up your body, it helps with allergies. Onions are good for chest congestion. Red onion is very good for the lungs.

For cold and flu symptoms, "use four limes, four red onions, cut in quarters, and boil garlic, the whole head cut in half, and you boil that and you strain it, and you drink that, and you feel like a million dollars in no time at all. You can put it in a gallon of water and drink it for a few days and you will feel a hundred times different." 
Every participant had a story to tell about "remedies passed down from generation to generation, like a chain, link to link." They were able to get many of the same herbs and teas that they got in a bodega in the Dominican Republic at a neighborhood store in their community. "There are 64,000 people living here, mostly Dominicans, and you will find any kind of ingredient, and you will combine it, and you have a remedy."

They described three supermarkets, one specific to tropical products, called the Tropical Supermarket. Here one can find a little section of over the counter medicines, brought from the Dominican Republic, like the Dominican version of Robitussin, made with onion. One of the participants brought out liquid in a bottle to heal knee pain (something with properties like icy hot). They explained that the bodegas have products imported from the Dominican Republic, but the government officials "conduct raids in town to clean out the bodegas of products that have not been approved here and they confiscate them. Just because it (the medicinal product) has not been through the whole legal process does not mean that it doesn't work." The participants spoke of herbs being of better quality in the Dominican Republic, and family members there often wanted them to smuggle drugs or herbs to the United States because they believed that the medicines were of better quality. They tell me that one grandmother got caught and fined $\$ 1000$, and the medicines and herbs were taken away from her. They said that there is no way to bring things here legally. These examples illustrate the strength of their beliefs. People are willing to risk legal 
consequences for using medicinal products from their homeland that are familiar to them.

A woman states "the medicine cabinet can cure just about anything. My aunt puts avocado seed in alcohol, rubbing alcohol, and lets it ferment for a week, and rubs it on muscle pain. You let the seed ferment and the alcohol will turn brown because of the seed being in there for a week, nine days, and then afterwards, if I have a sore muscle instead of rubbing Vicks or Ben-Gay, I rub the water (alcohol) and it alleviates the pain. Try the house remedy first, and the last resort is the doctor."

A young man described his grandfather in the Dominican who lives in the southern mountains, and is close to 100 years old. "There are a lot of Haitian people, and they know how to do cures. The Haitians come to work there, and they know how to cure people, some of them. My grandfather has never seen a doctor, his whole life, and he uses tea to keep him healthy."

These Dominicans prefer natural home remedies to maintain and protect their health, as well as for treatment of symptoms when they are sick. They know healers, and will use them when they feel it is necessary, but they don't talk much about this.

\section{Magico-Religious Practices}

In the one small English-speaking group of two participants, which was the second focus group, a woman and a young man spoke freely about voodoo and healers. In fact, the participants introduced the topic. The other groups did not want to discuss this topic at all, and became visibly uncomfortable with the conversation. They said they did not know about this topic (taboo!). Some even got up to leave. At 
the time that this happened, the group had been talking for almost two hours, and this topic was one of the last to be introduced. So it is not possible to know if the timing, or the topic, influenced the decision for participants to leave. When I discussed this with the two interpreters, who also acted as cultural brokers, they felt that the topic made the women uncomfortable, and this is the reason that they began leaving the apartment.

After meeting with the second focus group who revealed some voodoo practices to me, I introduced the topic to the third group. When I specifically told them that I knew these practices existed, and asked if they could tell me more about it, one participant responded. "If you believe in God, how can you believe in something like that, the bad can't be with the good. I accept that there are bad things and that the devil exists, I'm not saying they don't. But I believe if we have God, we don't have to be afraid."

In the small group, it was easier to elicit information about evil eye, spells, and spiritual healers or voodoo cures. The older woman, who was in her early sixties, was more willing to discuss this topic than was the younger male, 23 years old, who was also present in the group. He would agree, but was reluctant to tell his own stories about his personal experiences.

The woman described an experience that happened when she was a young girl with a toothache, when her mother called a Haitian man to the house to help her. She said that the man said a prayer, and removed the tooth with no instruments, and that her pain went away. When I asked what the man was called, and she responded, 
"They call him voodoo. I call it voodoo man.” Then both participants said, "They call them doctors, they are voodoo doctors." They then talked about how "they know how to do this in New York, and right here in our community, too. Santeria. I know people in New York, they don't have any place, but they know how to do everything." The female participant then gave another example of a woman that rented a room from her, and the woman would appear through closed and locked doors, when there was no other way to get into the room. "And she came through the door when the door was closed. And she used that shower up in the attic, and a whole bunch of oil, not water, was in the shower, Black Oil. I don't know what it was. My mom said that they use some kind of snake oil. They can squeeze themselves or something through the door, and you don't even know that they are there. I don't know, that's what my mom said, that she knows about that. (laughter)"

When I asked how one can find these people, I was told that "they are nice people you know, be friends with them, that's all, or stay away from them. If you need help, you find them." They are well-known in the Dominican community, but not outside of the group. If a stranger to the group needed help, I was told that the stranger would have to be accompanied by someone who knew the healer. "You have to go with somebody. They will not just help anybody, just like that. They have to get to know you first to see if you're OK. There's a level of trust that needs to be established." I was told that the healer will know your symptoms, you don't have to tell them. The woman told a story about a person who was envious of her, and put something in her beer. She said that she developed a cough for three months. "She 
put something in my drink. To kill me. I went to this person (a healer) and they gave me ruda, I don't know if you know ruda, but it's an herb, and they put it in a tea, for me to drink, and I vomited. I vomited like your shoe black, like pieces of something, and when I went to the bathroom, also it was black. And one day, all the sickness was gone and I never had a cough again, just like that. And he (the healer) told me that my mother's cousin put something in my beer. It was on Easter Sunday that I went to my mother's friend, and her cousin was there (when she started to get sick). So I do believe in that stuff." She states that the person who helped (the healer) knew what the problem was when she arrived. She did not have to tell them. She was told to stay away from the person who made her sick. I asked about the evil eye, as opposed to actually putting something into her drink, and she responded, "It's not a poison, it has something to do with whatever they do, you know, the voodoo. It could be the ashes of dead people, or somebody's hair, this and that."

"There are women that do bad things to the men, they put stuff in their food. My mother's cousin did the same thing to her boyfriends. She used to get the steaks, and put it in her private parts, and put it there before washing herself, and feed it to the guy. And the guy died from it. She did it for a long time, and she was putting it in his wine from her monthly, don't tell me that don't kill you. It killed the guy." "He was there every day, every day he was like a dumb person, he would do everything for her whenever she said. Whenever she said, he jumped. It was like a spell. She was into that stuff. I guess she grew up with that you know." When I asked if people feel 
uncomfortable using the word "voodoo," she responded, "Yeah, I guess I do." She said, "I call it superstition."

When I asked if one can get sick from a spell, this woman told me it's usually associated with something that is put into your food. The male said "I don't know nothing about this." He let the woman do the talking. However he later said, "I do believe this."

The woman told me another story to illustrate the concept of evil eye and spells, and perhaps voodoo cures, but at the very least, she demonstrated a magicoreligious belief system that is present in this Dominican culture. The female began, "I know because I have a lot of experience with this, I used to work at the hospital. She used to work here in the bank, the young girl, a Dominican, she was only 26 years old when she came into the hospital. She went to somebody's house to eat, they invited her, and she ended up in emergency room. And all you can see is the white part of her eyes and I kept saying what's wrong with her, what's wrong with her? And she couldn't breathe. She came out of that person's house. They intubated her. And she was in ICU for about three weeks. And they couldn't find nothing wrong with her. And something was telling me to go upstairs. The mother and the aunt, they knew me from church. So I said, can I go upstairs? Something was telling me, I didn't want to go, but something was pushing me. And I went upstairs, because I used to hand out the passes for people to go up, in the front desk there. So I went up, and I went and got the holy water with the ruda that they gave me, and I went upstairs and I grabbed her hand, and her hand was warm so I know she was okay. I could feel whatever she 
was going through. I started praying and people might think it's crazy but in three days she was out of the bed, and after the prayers, she said amen and her eyes came back. Her eyes came back. This was in ICU here in the hospital. In three days she was out of the hospital and back to normal. So I do believe that these people do bad things. I could feel it one night when I grabbed her hand."

When I asked if she is known as a healer in the community, she said this was the only time she was able to help in this way, but "there are people who know this, like at church. When we go to church, they say prayers there, you know, like they pray over your head like that. I go there and do that."

I asked how the medical people in the ICU, responded to the patient's improvement after she went to visit her, and she got better. She responded, "I don't know what they thought. Nobody asked me anything. They just went about their business. People don't want to see that. They're miracles." This may be an example of the providers' lack of knowledge about Dominican magico-religious practices, or it may demonstrate respect for the practice. It is not possible to draw any conclusions without further discussion with health professionals who provide care to Dominicans in this community.

The participant described things that make you sick as "some people think its spells, some people think it's related to what you eat, and some people think it's all about germs. It's probably a little bit of all of that. But when you go to a doctor, the doctor only wants to treat the germs... (talking about the girl in the ICU) they couldn't find anything wrong with her, nothing was wrong with her, and she was sick." When I 
asked the male if he knows anyone who got sick in the same way, he responded, "I hear people talking about this."

From this discussion with the participants it is obvious that the Dominicans are aware of magico-religious practices, and may or may not participate in the practice. There is a lot of superstition surrounding the practice, and not every participant was willing to talk to me about their beliefs regarding these practices. However, all of the participants use herbal remedies and plant-based teas to promote health and cure illness, independent of magico-religious beliefs and practices.

\section{Theme Four: Perceptions about the Quality of Professional Care Are Affected by Access to Care, Cost, Communication and Expressions of Caring Practices}

In the demographic survey, eleven people in the group reported that they used professional health care, but in the focus group discussions every participant described some encounters with professional health care, which included doctors, nurses, and hospitals. The topics of discussion focused on access to care, cost of care, communication with providers, and quality of care issues related to their experiences, expectations, and satisfaction with professional care.

\section{Access to Care}

Several obstacles related to access to care were identified by the participants. These include inconsistency with interpreters, lack of knowledge about available resources, and perceived cost. Inconsistency of interpreters affected patterns of communication, so that care felt fragmented. They felt that they had to "start over" to 
explain their feelings and circumstances every time there was a new interpreter that they did not know.

The participants spoke often about counseling, but also identified it as "taboo" in their culture. One woman described counseling in two ways: "In our culture, if you go for counseling, you are crazy. It is taboo. But my son said, mom, if you need it, you go there. They are professional. I think it needs to be more accessible, a lot of people don't even know that there is a clinic there." In a similar scenario, another participant said that there needs to be more information in the community about services, perhaps through a bulletin in church, where many people gather and trust the information that is given to them.

\section{The Cost of Professional Care}

When one woman walked into the mental health clinic and said that she did not have any money, the clinic asked her if she could pay ten dollars. She had a ten dollar co-pay each time she went, but she felt that it helped her quite a bit, and her adult children helped her with the payment so she could get professional help.

The participants said that one needs money to get professional health care in the Dominican Republic. It was described in this way: "A lot of people they are not going to the doctor because they don't got money, they don't got insurance to pay, maybe that's why they pray over there (in the Dominican Republic)." "Over there hospitals are public, and clinics are private. You can go to a hospital, but you have to pay for everything. If they are going to stitch you up, you have to buy the supplies. If you need infusions of intravenous you have to buy that yourself. So even though it's 
free, it's very costly. But then the clinic is for the rich. They're going to take care of you, they're going to have technology. They're going to have the best doctors. But you have to pay for it. You pay good money for that."

The Dominicans know that here, in the United States, they can go to the hospital and they will be taken care of. They don't worry so much about paying for it. "If you don’t have insurance, you can pay little by little. Over there you have to pay upfront, before they'll take care of you. Another problem, when you go to the hospital there, you got to pay before they'll take care of you. Here if someone has no insurance, they go to a hospital because they know that they don't have to come up with all of the money up front."

I asked how people felt about going to an emergency room when they have no money and no experience with professional healthcare, and I was told that "the people know a lot. They tell each other. You know, you can go here and you can pay little by little. The people know." So very often, the emergency room is where they go first, when the home remedies fail. They never see a private doctor. They describe the experience of having to wait a long time, which they expect, but they do not describe many negative experiences in the hospital. Some say that they had negative experiences in the past, but now they get patient surveys, and hospitals pay attention to their complaints, and they have learned to be more assertive, so they feel that the quality of care is better. 


\section{Communication with Providers}

In reference to a professional counselor, one participant says she would have preferred a Spanish-speaking psychologist so she could feel more open to express things. "If he was Hispanic, or if I knew English, we would communicate directly, but there's always a third person (interpreter). It makes me want to leave, but my doctor says I can't. I always have to talk to a third person, so that they can tell him what my problem is, and what I'm feeling, and to discuss personal problems, with a person that they just decided to send today... a new person...it is difficult."

Another participant described fragmented care, the pain specialist says one thing and the neurosurgeon says something different. She complained of lack of personalized care and consistency because the interpreters change with every visit. She felt a lack of confidence and privacy due to the language barrier between her and her psychiatrist. However, she was comfortable speaking about mental health, and it is usually taboo to discuss this, even among Dominicans themselves, due to stigma. There is a lack of coordinated care. She sees five doctors, and each prescribes some different for her treatment. "Generally, they have people that serve as interpreters, people that are able to translate. I feel there is something lost in translation, lost because you don't have that direct connection with the doctor. I will share my personal experience. I see a psychiatrist and he is Hindu. Just when I get comfortable with one interpreter they take her away. Every time I see him there is a different interpreter. As a result, it is difficult to gain confidence because the previous time I was there I had shared openly about my life and now I must repeat the same past 
experience with a new interpreter. I feel there is a lack of intimacy/privacy. Every time or at every subsequent visit there is a different person [referring to a new interpreter] this results in me holding back and not sharing all that I would have liked to. I feel prohibited and unable to fully open up. The same holds true for my medical condition. In 1998, I suffered an accident and have six herniated discs in my vertebrae." She goes on to explain the course of her treatment and the trial and error approach to solving her problems, which complicated her recovery. "I visit five physicians, and all of the doctors give me prescription medicine, and I can assure you that if I took all of the medicines prescribed by each of them that I would be seven feet under right now."

Another patient shares a more positive story about her cardiologist who is Hindu, but has two girls in the office who speak Spanish. She called the office when she felt that her newly placed pacemaker was "acting up." She was told to come to the office immediately, and the doctor told her the pacemaker was defective and immediately sent her to the hospital to be admitted. She states that the next day her doctor surgically replaced the pacemaker with one that has been working well for the past four years. "That is my doctor. He means the world to me." This is an example of a difference in spoken language between the patient and the doctor, yet the patient had a great deal of faith in her doctor. She has trust in her doctor who has cared for her for 12 years. The communication here may also be facilitated by the consistency of interpreters, since this Hindu cardiologist has two girls in the office who work there and speak Spanish. 
This participant said that most of the hospital staff speaks Spanish now. When she had open heart surgery, she learned that the hospital sends staff to learn Spanish, and it helps. The doctors and the staff joked with her when she was a patient here in a N.J. hospital, and it made her more comfortable.

\section{Experiences, Expectations, and Satisfaction with Professional Care}

Many participants shared their experiences when seeking professional health care that raised issues about the quality of care and how it is perceived by migrant Dominicans seeking care rendered by doctors, nurses, and hospitals. They shared their beliefs, expectations, and satisfaction with professional care encounters.

The participants felt that doctors are too quick to prescribe medicines, and do not want to explore to find a solution. "They just want to treat symptoms." "If we were better informed as to why they happen (conditions/symptoms), or what deficiencies in vitamins or hormones we have, then we would be better able to modify our own lifestyles." Some felt disappointed that they had to ask doctors to do tests for diagnosis.

One participant illustrated her preference for natural remedies over prescription drugs by revealing that she preferred the clinic to the private doctors here, because "they are with the pharmaceuticals." She was impressed with a nurse in the clinic who told her daughter to try primrose, obtained over the counter, for menopausal symptoms, rather than a prescription, and it worked for her.

The participants reported their perception that in the United States, "doctors are board members of pharmaceutical companies, and have an interest in the 
company." They felt that the doctors should try to investigate by communicating better, and not be so willing to prescribe medicine as quickly as they do. One participant felt that there was fragmented communication between doctors that may lead to over-medication or unknown drug interactions, and she must be an advocate for herself. This participant explained her experience with adverse reactions to prescribed medication, and says it is a personal responsibility to advocate for oneself, and participate in decisions about taking medicine. She advised that one should be cautious with prescribed medication, be assertive, and willing to voice concerns. She believes no one can be forced to take a medicine just because the doctor ordered it, especially in the hospital. "The doctor ordered it, but the decision to take it is mine, and I say "NO!"

The participants identified differences in the way they are treated by doctors here, in comparison to the Dominican Republic. In the Dominican, the doctors spend more time with patients, and the participants felt that the doctor cared about them in a way that is different from what they experienced in the United States. In general, they felt their doctors here needed to be more personal and to spend more time with them to try to communicate better. They appreciate the Dominican and Cuban doctors that they have, because they take time and listen to them. They explain that in the Dominican Republic, you see a doctor, and they take a history of your life. "They take their time with the patient. Here, everything is mechanical, more than ever because of the computer. With the computer in front of them, they don't even look at your eyes. I feel as if...I don't know, as if they don't explore, they don't investigate, I can't explain 
it." The participants felt that they needed more open communication between the doctor and the patient. They felt things could be better if there was a better system that pays more attention and is more personalized. "Physicians should ask more questions to the patient about how they are feeling."

The participants felt that they had some recourse to improve the quality of the care they received, and also to help themselves, by acting as an advocate for other migrant Dominican patients. One participant felt that she would like to volunteer to help the elderly in nursing homes, and described her role as an advocate for them. By giving back, she explained, it helps her to feel more productive. She explained that in her own way, as a volunteer, she could speak up for the patients if she saw that they had unmet needs or problems. As a volunteer, she believes that there will be no negative consequences for her if she speaks up for the elderly patients.

Another elderly participant described her hospital experience years ago, and said that she felt neglected in the hospital, that the nurse hated her, and she was ignored. She said, "that was back then, but if it happened now, I would act differently. I would complain, I would let them know because that is not fair." She described the need to feel cared for by the nurse in the hospital. Her nieces came to the hospital and cared for her. She says that if someone complains today, the hospital pays attention. If it happened again, she would ask for a new nurse, and complain until they changed the nurse. She sees improvement with the ability to give feedback about the service (consumer satisfaction surveys). In her opinion, these surveys redirect how hospitals and doctors administer their services, because of that feedback. "It gives quality." 


\section{Chapter V DISCUSSION}

This research discovered and described migrant Dominican cultural beliefs and practices related to health, ways that Dominican migrants take care of their health, and their experiences with professional health care in the United States. The focus groups supported some findings from other studies and facilitated increased understanding of perspectives in this migrant Dominican population that were previously not well documented in the literature. Four themes emerged in the findings: (a) stress affects health and well-being, (b) family support and faith in God are essential for healing, and promoting health and well-being, (c) migrant Dominicans use both folk care and professional care to treat illness and promote healing, health, and well-being, and (d) perceptions about the quality of care are affected by access to care, cost, communication, and expressions of caring practices.

\section{Theme One: Stress Affects Health and Well-Being}

The migrant Dominican participants clearly articulated their belief in the negative impact of stress on their health, and identified some strategies for coping with this stress. They strongly believe that good health is related to quality of life, and can be maintained by a balance of work, recreation outdoors, and adequate rest, minimizing stress with lifestyle changes, eating wholesome and nutritious food in proper amounts, feeling satisfaction from being productive in work, and leading an 
active life. For these migrant Dominican participants, promoting good health had more to do with lifestyle and quality of life, than anything else.

Easter, Linnan, Bentley, DeVellis \& Meier (2007) identified stress similar to what these migrant Dominican women experienced. Latina women reported stress from double work inside and outside the home. The Latinas in their study felt that here in the United States, a woman works two or three times as much as in her country of origin. The migrant Dominican participants in this study gave examples that support D’Alonzo's (2012)findings regarding acculturation stress, lack of social support, and role overload associated with lifestyle when Latinas migrate to the United States, that lead to limitations in planned exercise activities. Role overload is described as "more tasks to do and less help with which to do them than in their home country." (p.129) Concurrent with the findings of D'Alonzo, the women were less likely to have worked outside the home prior to immigrating to the United States, and work was a major source of stress for them now. They "lamented the loss" of their friends and extended family members who would have been a source of social support for them, especially with the added responsibilities of working outside the home. D'Alonzo described it in the words of the women in her study as "life is too fast here" (p. 128). Congruently, a combination of these factors led to a more sedentary lifestyle and adversely affected women's physical activity behaviors, and opportunities to optimize their health.

The findings of this study related to a difference in the diet and quality of food between the Dominican Republic and the United States support literature from Siatkowski (2007) that suggests low acculturation levels are linked to healthier eating 
habits such as higher dietary fiber intake and lower dietary fat intake than those with higher levels of acculturation. Although Siatkowski describes many factors to assess acculturation, the acculturation process in most of these participants was limited by living in an ethnically Dominican neighborhood in the United States. Many of the participants in this study have lived here at least half of their lives, and they continue to miss the native food of their homeland.

Based on this discussion, it is possible that providing an affordable source of organic food, facilitating more bridges for social support within their community, and identifying pathways to professional mental health services will aid in reducing the level of stress in this group.

\section{Theme Two: Family Support and Faith in God Are Essential for Healing and Promoting Health and Well-Being}

The expressions about familismo from the migrant Dominican participants in this study are collaborated by Shedlin \& Shulman (2004, p. 439) who quoted an HIV positive participant in their study: "For those of us who are infected, you don't know how important the family is for us; the family can help to cure without medicine even the most terrible physical pain." Substantiating the value of family in the Dominican culture, studies done by Schumacher (2010) and Holt (2000) also validate the importance of family and relationships for social support, caring and healing. The concept of family may also include "community family" when blood relatives are not present. 
Faith in God, religious beliefs, and prayer give Dominicans a sense that they are protected and not alone in their physical challenges. If they experience illness, these Dominicans say that they are willing to choose healthy behaviors to help God to heal them, if that is His will. Some have had powerful near-death experiences that they described, and they felt no fear, only stronger faith that death will bring a peaceful eternal life, as promised by their faith. Faith helps them to accept that illness is a test from God and they have to help God with his plan for them. The findings in this study support the research done by Nui et al. (2011), that examined how patients with advanced arthritis are affected and cope with their disease. Accordingly, arthritis represented God's way of testing their faith, and they trusted that demonstrating their faith would ultimately convince God to cure their illness. A patient in Nui's study described arthritis as "a test to see if I can continue fighting or not" (p. 5). Similar to the expressions of faith from migrant Dominican participants in this study, Florez et al. (2009) indicated that positive views on breast cancer and screening are produced and maintained through a complex framework of inner will and external forces that allow both survival and death to be possible from breast cancer. "En la lucha" referred to the ongoing process of persevering, dealing with, and fighting against adverse health and other events in which willpower and self-reliance to overcome hardships was expected. The participants expressed faith in God's intervention, but took responsibility for their own life outcomes via the cultural framework of "luchar (to persevere)" (p. 298). Luchar centers on the belief in one's ability to fight and defeat adversity as an active coping process. Like the migrant Dominican participants 
in this study, the women in the Florez et al. study saw themselves as proactive agents in their health care, thereby influencing their illness destiny.

Furthermore, the Dominicans in this study described the power of prayer and faith in God to heal and bring solutions to problems. This is congruent with Babbington et al. (1999) finding that "practices such as prayer, the use of sacraments, and paying homage to special saints and holy images were viewed as integral to good health and disease prevention and treatment" (p. 24) in the rural Dominican Republic.

These findings are further supported by Holt (2000) who explored the concept of hope within the Dominican culture from data gathered in a rural village in the Dominican Republic, which was similar to the beliefs described by Nui et al. (2011), and Florez et al. (2009). Faith in God, as described the migrant Dominican participants in the present study, is conceptually identical to the concept of hope described by Holt (2000). According to Holt, the Dominican concept of hope is "an essential but dynamic life force that grows out of faith in God, is supported by relationships, resources and work, and results in the energy necessary to work for a desired future. Hope gives meaning and happiness" (p. 1124). Congruent with the beliefs expressed in this study, Holt discovered that some informants could not conceive of a person without hope (or faith in God), while for others, hopelessness was a theoretical possibility which they could not imagine ever being a reality (p. 1121). This finding speaks to a health-related belief system of hope and faith in God to choose the best path for them that was discovered in this study and that is found in the literature among all Dominicans, regardless of where they live. The findings in 
this study are the same as findings about Dominicans in the rural DR, and continue to be to be similar when Dominicans migrate to a new environment, regardless of the amount of time spent in the new country, indicating that these beliefs are deeply embedded in Dominican culture.

The participants in this study preferred the priest as an advisor and counselor over a professional because they feel a stronger connection with the priest and believe that he knows them and their circumstances better than anyone else would. Providers should acknowledge the role of family support and faith in God to promote healing, health and well-being when developing a plan of care. The positive action strategies for empowering women that were suggested by the participants to improve health and decrease stress within the group and the community should be embraced by health care providers. Nurses, especially parish nurses, who are part of the core of the faith community, can offer support to implement the participants' suggestions in the community. They suggested starting Spanish-speaking book clubs focused on discussions about empowering women with positive thinking, and providing companionship to lonely elders with human presence or pet therapy. Additional recommendations based on the faith community include forming church community networks to transport people to medical appointments and therapy, and training and using bilingual church community members as patient advocates who can interpret and translate for the Dominican client to improve communication. 


\section{Theme Three: Migrant Dominicans Use Both Professional and Folk Care to Treat Illness and Promote Healing, Health, and Well-Being}

The findings from this study are consistent with the literature reporting the use of natural home remedies as the primary source of promoting health and treating illness both in the Dominican Republic and after the migrant Dominicans settled in the United States (Allen et al., 2000, Fugh-Berman et al., 2004, Leininger, 1997, Ososki et al., 2002, Schumacher, 2010, and Vandebroek et al.. 2010).

Complementary and alternative medicine (CAM), as described in the literature, is conceptually equivalent to generic (folk) medicine, which was previously described as "care that is based on traditional, folk, lay, indigenous, local, home or alternative caring practices and skills that have been used by people, families and communities over time, and have been known and valued as first use, naturalistic, familiar, and beneficial healing skills and practices" (Leininger, 1997, p. 36). The Dominicans strongly believed that herbal teas and natural home remedies were the first line of defense against illness and disease, and often delayed seeking professional care for this reason.

Congruent with the findings presented in this study, Vandebroek et al. (2010), Ososki et al. (2002), and Fugh-Berman et al. (2004) found the use of medicinal plants prescribed by Dominican healers in New York City, and Ososki et al. documented changes in plant use as people migrate to urban centers where they are surrounded by diverse cultures, healing systems, and new environments. Allen et al. (2000) found complementary and alternative medicine (CAM) users to be female, longer-term 
residents of the United States, who also used religious practices for health problems, and suggested that CAM is a less expensive way for migrant Dominicans to treat health problems. Supporting the relevance of this study, Allen et al. stated that "it is also possible that some patients are not satisfied with aspects of the U.S. health care system, thus increasing their reliance on traditional medicines" (p. 53).

Two of the participants described believing in magico-religious practices to cure illness. I was told by the interpreters, who acted as cultural brokers, that there was superstition surrounding the practice of voodoo. Everyone knows about it, but usually it is not discussed, even among people who know each other. The interpreters were surprised that the topic was introduced in one focus group, and that the participants were willing to talk to me about it. Participants in other focus groups acknowledged that some people believe in this, or they know that it exists, but that they had nothing to say to me about it. This suggests that there is a powerful magicoreligious belief system that exists and is surrounded by superstition, but it may not be believed or used by all Dominicans, or they may not be willing to discuss it with people outside of their own community.

Shedlin and Shulman (2004) explained that people in rural areas of the Dominican Republic do not have access to professional health care, and therefore they are unfamiliar with this type of care and do not expect or seek it in the United States. This idea may be carried over to their health beliefs and practices in the United States, and they suggest that migrant Dominicans may not understand or value preventive health care. In their country, with a magico-religious belief system that is embraced 
by many, the will of God, or supernatural forces of good and evil may have more to do with health care outcomes than other factors. However, this did not seem true for the participants in this study, as all of them used professional health care as well as traditional folk care such as teas and home remedies.

The use of voodoo as described by two participants is consistent with findings from Babbington et al. (1999), reporting that disease and illness were often attributed to supernatural causes such as bad luck, black magic, voodoo and spells, and there were many recipes for dealing with the magico-religious causes of illness in the rural Dominican Republic. Only two participants discussed voodoo practices, while the members of the Spanish-speaking focus groups appeared uncomfortable with the topic and were unwilling to talk about it with me.

It is unknown why some of the participants were willing to talk about voodoo practices in depth, some acknowledged that it exists, and others did not want to discuss it. However, no one denied having knowledge of this practice. The interpreters who also acted as cultural brokers believed that discussing voodoo in the focus groups indicated and validated that trust and rapport with the researcher had been established. They stated that even within Dominican culture, most Dominicans will not speak to outsiders, or even to each other, about voodoo practices because of the superstition that surrounds it.

My curiosity for an explanation about what happened in the focus groups invited me to do further research in the literature, and to examine voodoo within the context of the history and politics of the Dominican Republic. From a historical 
perspective, the Dominican Republic was first conquered by Spanish explorers who introduced Catholicism, which continues to have a strong presence in the daily lives of the people. Later, African slaves arrived, and brought their tribal beliefs along, which mixed with local practices resulting in the current practice of voodoo (Babbington et al. 1999). Voodoo is a religious folk tradition of the Dominican Republic that is widely practiced, and "its practitioners, mostly rural dwellers and the urban lower class, are devoted to its powers in resolving illness and problems of everyday life" (Davis, 2007, para. 2).

Davis (2007) describes a practice that blends both beliefs into folk-Catholic rituals, where the Catholic component precedes the African-derived or Creole components, which is also true in Haiti. According to Dominican beliefs, there is a structure of "the necessary before the important" (para.7). For example, "the rosary before the drumming" (para.7) Commonly, strong faith in God and magico-religious beliefs are practiced together. The Dominican world view transcends social class and region, according to Davis, and when it becomes necessary, "even the more Hispanic affluent class seeks out mediums to appeal to the voodoo deities and their mysterious powers of divination and healing" (para.2).

Dominicans and Haitians have been historical enemies. Apodaca-Valdez (2012) explained that the Dominican Republic has a long history of external occupation and internal struggle, governed as a dictatorship under Trujillo (19301961), and later under President Joaquin Balaguer, who was re-elected three times (1960-1962, 1966 -1978, and 1986 to 1996). These governments attempted to impose 
a "whitening" ideology, or "a psychological process unconsciously motivated by an economic state of underdevelopment, which blames minorities, blacks and Indians for being the cause of backwardness of the country" (Apodaca-Valdez, 2012, para. 1), essentially marginalizing this population and their magico-religious beliefs. According to Apodaca-Valdez (2012), "related to various historical periods and their respective governments, African influence in the Dominican Republic has been denied" (para. 1). However, Haiti and the Dominican Republic share a common border, and despite the difference in language and customs, a "constant and uninterrupted process of trade and cultural exchange between the two countries permeated deep into the culture and society of each of them" (Apodaca-Valdez, 2012, para. 3). Given this political perspective, open conversation about the practice of voodoo may have been injudicious during the time most of the participants lived in the Dominican Republic, and persisted when they migrated to a new environment. It is also interesting to note that the participants who did speak of voodoo also said the practitioners were Haitian.

I discovered that in the Dominican Republic, the practitioners do not call their practice "voodoo." According to Davis (2007, para.4):

Researchers should be warned not to use the term because universally, in the Dominican Republic, "voodoo" implies black magic of Haitian origin, the work of the Devil rather than of God. Although all scholars use the term voodoo, the vast majority of their Dominican practitioners prefer different names like Blackjack Division, "believe in the mysteries," or "believe in the 
heal," and designate this activity as magical-religious. The Dominican medium Jovanny Guzman says, "It really is voodoo, but we cannot say it because of the Dominican rejection of Haiti."

This explanation is consistent with folk religion or magico-religious beliefs, and the words of one of the participants in this study: "If you believe in God, how can you believe in something like that, the bad can't be with the good. I accept that there are bad things and that the devil exists, I'm not saying they don't. But I believe if we have God, we don't have to be afraid."

In summary, I can conclude that some of the participants in the focus groups were aware of the practice, and that some Dominicans practice voodoo for healing in addition to herbal remedies and prayer. The fact that two of the participants were willing to talk about voodoo suggests that a high level of trust had been established with these participants, perhaps because it was a smaller group. Despite the fact that I used a neutral, non-judgmental approach to encourage the participants in other focus groups to describe their knowledge of voodoo practices, they were unwilling to talk about this topic, even in the context it was presented. It is notable that information about magico-religious beliefs and practices was revealed only in the smallest group of two participants; therefore, conducting individual interviews with participants may elicit more information about this topic. Providers need to learn more about folk care practices, including voodoo, to determine what is being used to treat the current illness, and plan care accordingly to include these practices. 
Theme Four: Perceptions about the Quality of Professional Care Are Affected by Access to Care, Cost, Communication, and Expressions of Caring Practices

Migrant Dominican participants do not know where they can go for care, especially mental health services. Migrant Dominican participants need help to pay the cost of services. Communication is fragmented and affects care, but many found a growing number of Spanish speaking health care providers, nurses, and assistants in doctor's offices to accommodate them. Communication and therapeutic intervention is altered by a frequent change in interpreters, and creates stress due to lack of consistency and limitations to building a relationship.

Jacobson, Chu, Pascucci and Gaskins (2005), report that cultural competence requires willingness and skills to adapt and negotiate policies and procedures to the mutual satisfaction of the health professional and the care recipient. Yurkovich, Clairmont \& Grandbois (2002) concur that cultural responsiveness requires a person to create culturally congruent care through collaboration with clients. This is a value presented by the Dominicans in this study, who want doctors to spend more time with them and listen to their health history and complaints. They preferred natural remedies to pharmaceuticals, and wanted the doctors to accommodate them, or to offer nutritional advice or lifestyle changes that could improve their health.

Among the significant findings of another study, Chinese and VietnameseAmerican patients wanted to discuss the use of non-Western medical practices with their providers but encountered significant barriers (Ngo-Metzger et al., 2003). They viewed providers' knowledge, inquiry and nonjudgmental acceptance of traditional 
Asian medical beliefs and practices as part of quality care. From the patients' perspective, important aspects of quality for them included providers' respect for traditional health beliefs and practices, access to professional interpreters, and assistance in obtaining social services. Congruently, the migrant Dominican participants did express a desire for consistency with interpreters and assistance in obtaining social services for financial reasons when they needed professional care. The participants in this study did not mention wanting to discuss the use of home remedies with their health care provider, but they did value natural remedies over pharmaceutical drugs that were often prescribed by doctors in the United States, and were willing to risk legal consequences to obtain them.

When Suurmond and Seelemen (2006) interviewed immigrant patients and physicians in the Netherlands to elicit information about conceptual barriers to shared decision-making between them, they found that due to the barriers (different linguistic background, different values about health and illness, different role expectations, and prejudice and not speaking to each other in an unbiased manner), the communication and the shared decision-making process was impeded. This is a similar concern among the migrant Dominican participants and should be addressed to raise awareness among health professionals to overcome these barriers and improve communication.

According to Zoucha (1998), Mexican Americans described care as personal and friendly when a nurse was attentive and took time with them, as well as trying some words to communicate in Spanish. The migrant Dominican participants in this study shared the same perspective. Mexican American informants explained that they 
always have confidence in family or friend caregivers because they are compadres, and the nurse must earn the confidence of the Mexican American client when providing professional care. Confidence involves the process of the nurse becoming personal with the client, leading to health and well-being for the Mexican American client (p. 40). "This confidence is shared by the nurse and client, and empowers both to take responsibility for health promoting actions and decisions" (Zoucha, 1998, p. 40). The participants in the Dominican study also indicated that they value a relationship with the health care provider that empowers both to take responsibility for health promoting actions and decisions.

According to Schumacher (2010), relationships with Dominicans must be established to build trust that will ultimately lead to collaboration with professionals regarding their care, and culture care repatterning and restructuring may not be possible until the professional first applies the concepts of culture care preservation or maintenance and/or culture care accommodation and negotiation (p. 99) for this reason. Congruently, this paper presents the concept of culturally responsive care, which requires a reciprocal relationship between the client and the provider, and applies repatterning/restructuring to the professional practice of the provider as well repatterning behaviors on the part of the Dominican recipient of care.

In the present study, caring was perceived as "presence" and "taking time with me," and "listening." These migrant Dominican participants were aware of hospital satisfaction surveys to give feedback and promote quality of care. Professionals need to provide education in the community and raise awareness of where Dominicans can 
find appropriate services, how they can get financial assistance to pay for it, and how to advocate for themselves with patient care issues. In addition, providers need education to raise awareness about the needs of migrant Dominicans in this community and the best approach to providing care for them.

The people in Purnell's studies $(1999,2001)$ were similar to the migrant Dominican participants in valuing verbal and non-verbal communication that demonstrated respect. Congruent examples of respect from both the Central Americans and the migrant Dominican participants included "the way the health care provider talks to me," and "gives me complete information," "has presence," "sincere," "friendly," "is completely dedicated to me at the time of treatment," and "treats me like a human being." They collectively described disrespect or dissatisfaction with health care providers as "gives little attention," "is insincere," "does not look me in the eye," and "does not greet you." Although the migrant Dominican participants perceived that some of these behaviors were related to the use of ever-changing interpreters, perhaps their perceptions reflect the more universal value of a need to be respected. Verbal, and especially non-verbal behaviors, can convey respect, even when language barriers exist, so health care providers should maintain vigilant awareness of conveying respect accordingly. Congruently, Schumacher's (2010) Dominican informants described "showing respect and offering one's attention as the best way to express care to another individual" (p. 98). Other ways to indicate respect included listening, explaining information, acknowledging 
them, and addressing individually expressed needs and concerns with undivided attention from the care provider.

Warda's findings (2000) indicate that health care providers need to take into account personal, cultural, and environmental context when providing care to Mexican Americans. Similar to the migrant Dominican participants, Warda's focus group participants identified culturally defined concepts (personalismo or formal friendliness and valuing), cognitive/perceptive concepts (knowledge of US health care system), and system-related concepts (system barriers such as acknowledgement of the importance of family involvement, respect for use of cultural beliefs and practices like folk medicine, emphasis on interpersonal rapport, and understanding of life circumstances and economic constraints) related to their perception of culturally competent care. Warda's Mexican American participants emphasized respect, caring, understanding and patience in health care encounters that make it possible for them, as recipients of health care, to deal with health-related issues successfully or on similar terms with the U.S. population. 


\section{Chapter VI \\ IMPLICATIONS FOR NURSING PRACTICE, RESEARCH AND EDUCATION}

This study is one of the first to explore the health-related beliefs, practices, and experiences of the rapidly growing Dominican population living in the Northeastern United States, and one of the first to give voice to the Dominican client's experience with professional health care in the United States. The results of this study have the potential to shape clinical practice in order to better meet the needs of this group. Better understanding may improve the quality of care provided, and may also improve patient-provider trust and communication, as well as help patients adhere to prevention and treatment plans (Caballero, 2007). In addition, the findings of this study may lead to more culturally responsive professional health care for Dominicans, and help reduce health disparities in this group. Findings from this study may also contribute to meeting the objectives of Healthy People 2020: to achieve health equity, eliminate disparities, and improve the health of all groups; to create social and physical environments that promote good health for all; and to promote quality of life, healthy development and healthy behaviors across all life stages (Centers for Disease Control and Prevention (CDC), 2011).

The findings of this study support the Theory of Culture Care Diversity and Universality that predicts "if nurses fully understood generic care in different cultures, 
and used it appropriately with professional care, one would find therapeutic or beneficial healing outcomes" (Leininger, 1997, p. 36). Using Leininger's three theoretical action modes as a framework, the findings of this research can be translated into an action plan that seeks to eliminate health care disparities and improve the quality of health care for migrant Dominicans in this community.

In Leininger's Theory of Culture Care Diversity and Universality (1997), three action modes are identified as (a) culture care preservation/maintenance, that helps cultures preserve beneficial practices; (b) culture care accommodation/negotiation, that helps people adapt or negotiate with others for culturally congruent or culturally responsive care; and (c) culture care repatterning/restructuring, that helps people to change or restructure practices for beneficial outcomes. Table 3 provides strategies to improve professional health care for this group of migrant Dominicans, using the concept of culturally responsive care and Leininger's three action modes. 


\section{Table 3}

\section{$\underline{\text { Strategies for Culturally Responsive Care Using Leininger's Three Action Modes }}$}

\section{Culture care preservation/maintenance}

- Plan a community garden for fresh organic food, outdoor activity, and socialization

- Include the priest for endorsement and support of professional services

- Use parish nursing for prevention and early intervention screening

\section{Culture care accommodation/negotiation}

- Plan group walks, outings, or exercise classes to include family and friends for recreation, socialization and motivation

- Plan activities during time off from work to promote relaxation

- Use church community members to help with transportation and care

- Make accommodations for the presence of prayer groups or prayer circles to promote healing

- Educate professional care providers to learn about Dominican folk care practices in a non-judgmental manner to determine what is being used to treat the current illness

- Negotiate with Dominican clients who use medicinal tea, to limit tea consumption (certain amount per day) and also use pharmaceutical medicine concurrently

\section{Culture care repatterning/restructuring}

- Hold open office hours, rather than specific appointments with care providers, to accommodate a more relaxed concept of time

- Plan open screenings rather than private consultations, in church communities (blood pressure, diabetes, nutrition, social services) to accommodate family support

- Include the family in planned interventions (teach care to family members vs. self-care)

- Publicize professional care services, especially for mental health, in churches and Dominican community gathering places like the Tropical supermarket or the Senior Building

- Use social workers to facilitate assistance with the cost of professional care and prescription medicine, and publicize this in gathering places in the community

- Use consistent interpreters or train and employ members of the Dominican community to translate for professional care providers

- Allow Dominican clients to bring a personal advocate to translate

- Increase awareness of caring practices among professional providers, such as "presence," and "spending time with me," and "listening attentively," to build relationships with Dominican clients

- Educate the professional care provider to be aware of verbal and especially non-verbal behaviors that communicate interest and respect for the Dominican client 
The Constitution of the World Health Organization (2006, p.1) defines health as "a state of complete physical, mental and social well-being and not merely the absence of disease or infirmity." Congruently, Leininger (1997, p. 38) defines health as "a state of well-being or restorative state that is culturally constituted, defined, valued, and practiced by individuals or groups, that enable them to function in their daily lives." The findings from this research indicate that the migrant Dominican participants reflect both of these definitions in their beliefs, practices, and experiences with professional health care. Furthermore, the World Health Organization (2008) defines the social determinants of health as:

The circumstances in which people are born, grow up, live, work and age, and the systems put in place to deal with illness. These conditions in which people live and die are, in turn, shaped by political, social, and economic forces" (p.3). Concurrently, the Dreyfus Health Foundation's Problem Solving for Better Health (PSBH) program provides innovative methods that consider these social determinants of health, and promote grass-roots solutions to pressing heath issues by directly involving the community in the process (Smith, 2011). The underlying principle is that "the people" must take ownership of the problems they face and make a commitment to be actively involved in the solutions they need to improve health and quality of life. In essence, this program has been successful by asking the community to define and prioritize the problem, to identify and sort out possible solutions, to develop an action plan, and take action (Smith, 2011). In addition to following the recommendations from this study using Leininger's three action modes, it is possible 
that additional research and specific training in the PSBH method for key community members has the potential to solve problems that were initially identified by the participants in this study.

Continued research with migrant Dominicans in their preferred language is needed to add to the body of knowledge about this population. According to Williamson et al. (2011), evidence that interpreter-facilitated interviews can be both effective and affordable is relevant for researchers in migrant receiving societies such as Canada, the United Kingdom, and the United States. "In an effort to continue advancing knowledge about social phenomenon in these societies, it is essential that social scientists design studies that increase the extent to which an ethno-culturally and linguistically diverse range of voices, perspectives and experiences are elicited" (Williamson et al., 2011, p. 391-92).

Based on the findings from this study, more research should be done with migrant populations in their native language to close the gaps in the literature. Culturally appropriate bilingual interpreters should be involved in the study design and valued as significant contributors to facilitate the research process from the beginning to the end. The importance of the culturally appropriate interpreters in this study was not fully appreciated until the study was in progress. Their value in building trust, acting as cultural brokers, ensuring successful communication, and contributing to accurate data collection and interpretation was unexpected, and cannot be minimized in future research. The design and implementation challenges from this study, and 
strategies used to bridge cultural and linguistic barriers, may guide others in planning research with similar populations.

In addition to the strengths and limitations of the study that are cited throughout the manuscript, several require additional mention. The focus group approach provided opportunity for a collective perspective, and discussion in the group allowed synthesis and validation of ideas and concepts as the study was evolving. In addition, the fact that the researcher was not Dominican helped to curb bias from Dominican interpreters in the study. The use of interpreters could have been a limitation; however, I minimized the limitation of using interpreters by carefully preparing them prior to commencement of the study, and using debriefing discussions after the focus group sessions to improve the techniques for the next groups. The bilingual Dominican interpreter informed the researcher when questions were considered culturally inappropriate, allowing for a harmonious flow of conversation in the focus groups. Careful preparation of the selected interpreters, and maintaining an awareness of the ways in which data could be affected when interpreters assist in focus groups, was a pre-requisite for the collection of reliable, valid and rich data, as well as sensitive data interpretation, lending strength to this study. Interpreters facilitated access to a group that was under represented in the literature due to linguistic barriers, and allowed the researcher to have access to a wider range and number of participants.

Breach of confidentiality among the focus group participants was a possibility because I could not prevent other group members from sharing information from the 
discussion with people outside of the group. Therefore, this possibility may have influenced the level of disclosure and comfort in group discussion. In addition, the findings cannot be generalized to all Dominicans living in the United States based on the small group of Dominicans who participated in the study.

The detailed descriptions of demographic characteristics, and rich, thick descriptions of themes provide a basis for comparison in future research studies. In this study, the interpretations of the health-related beliefs, practices, and experiences of migrant Dominicans in this Latino community may be transferrable to other ethnically Dominican communities in similar cities in the United States, but may differ in ethnically diverse communities due to the processes of acculturation and assimilation. Further research is needed to determine conditions for migrant Dominicans in other parts of the United States, to contribute to the body of transcultural nursing knowledge about Dominicans, and to amplify the voice of this population in the literature. 


\section{REFERENCES}

Agency for Healthcare Research \& Quality (AHRQ). (2001, November). Diabetes disparities among racial and ethnic minorities fact sheet (AHRQ Publication No. 02-P007). Retrieved September 1, 2011, from Agency for Healthcare Research \& Quality (AHRQ): http://www.ahrq.gov

Allen, R., Cushman, L., Morris, S., Feldman, J., Wade, C., McMahon, D., . . . Kronenberg, F. (2000). Use of complementary and alternative medicine among Dominican emergency department patients. American Journal of Emergency Medicine, 18, 51-54.

Apodaca-Valdez, M. (2012). El vudu dominicano: Religiosidad, magia y cultura. Delaware Review of Latin American Studies, 13(2).

Aponte, J. (2009). Diabetes-related risk factors across Hispanic subgroups in the Hispanic health and nutritional examination survey (1982-1984). Public Health Nursing, 26(1), 23-38.

Babbington, L., Kelley, B., Patsdaughter, C., Soderberg, R., \& Kelley, J. (1999). From recipes to recetas: Health beliefs and health care encounters in the rural Dominican Republic. Journal of Cultural Diversity, 6(1), 20-25.

Caballero, A. (2007, April). Cultural competence in diabetes mellitus care: An urgent need. Insulin, 2(2), 80-91.

Cagle, C. S. (2006). Student understanding of culturally and ethically responsive care: Implications for nursing curricula. Nursing Education Perspectives, 27(6), 308-314.

Campinha-Bacote, J. (2003). The process of cultural care competence in the delivery of healthcare services: A culturally competent model of care (4th ed.). Cincinatti, OH: Transcultural C.A.R.E. Associates.

Carter, J., Pugh, J., \& Monterrosa, A. (1996). Non-insulin-dependent diabetes mellitus in minorities in the United States. Annals of Internal Medicine, 125(3), 221232.

Centers for Disease Control and Prevention (CDC). (2011, October 14). Healthy People 2020. Retrieved December 29, 2014, from Centers for Disease Control and Prevention: http://cdc.gov/nchs/healthy_people/hp2020.htm 
City-Data.com. (2015). Races in Perth Amboy, New Jersey (NJ) Detailed Stats: Ancestries, Foreign born residents, place of birth. Retrieved January 30, 2015, from City-Data.com: http://www.city-data.com/races-Perth-Amboy-NewJersey.html

Clarke, A. (1999). Focus group interviews in health care research. Professional Nurse, 14, 395-397.

D'Alonzo, K. (2012). The influence of marianismo beliefs on physical activity of immigrant Latinas. Journal of Transcultural Nursing, 23(2), 124-133. doi: $10.1177 / 1043659611433872$

Davis, M. (2007). "Vodu" of the Dominican Republic: Devotion to "la veintiuna division." Afro-Hispanic Review, 26(1), 75-90.

Easter, M., Linnan, L., Bentley, M., DeVelles, M., \& Meier, A. (2007). Una mujer trobaja doble aqui: Vignette-based focus groups on stess and work for Latina blue-collar women in Eastern North Carolina. Health Promotion Practice, 8, 41-49. doi:10.1177/1524839905278916

Ely, M. (1991). Doing qualitative research: Circles within circles. London and New York: RoutledgeFalmer .

Ennis, S., Rios-Vargas, M., \& Albert, N. (2011, May). The Hispanic population: 2010 Census briefs. Retrieved April 1, 2013, from http://www.census.gov/prod/cen2010/briefs/C010br-04.pdf

Florez, K., Aguirre, A., Viladrich, A., Cespades, A., De La Cruz, A., \& AbraidoLanza, A. (2009). Fatalism or destiny? A qualitative study and interpretive framework on Dominican women's breast cancer beliefs. Journal of Immigrant Minority Health, 11, 291-301. doi:10.1007/s10903-008-9118-6

Fugh-Berman, A., Balick, M., Kronenberg, F., Ososki, A., O'Connor, B., Reiff, M., . . . Lee, R. (2004). Letter to the editor/Treatment of fibroids: the use of beets (beta vulgaris) and molasses (saccharum afficinarum) as herbal therapy by Dominican healers in New York City. Journal of Ethnopharmacology, 92, $337-339$.

Getaneh, A., Michelen, W., \& Findley, S. (2008). The prevalence of cardiovascular risk conditions and awareness among a Latino subgroup: Dominicans in Northern Manhattan. Ethnicity \& Disease, 18(3), 342-347. 
Halcomb, E., Ghlizadeh, L., DiGiacomo, M., Phillips, J., \& Davidson, P. (2007). Literature review: Considerations in undertaking focus group research with culturally and linguistically diverse groups. Journal of Clinical Nursing, 10001011.

Holt, J. (2000). Exploration of the concept of hope in the Dominican Republic. Journal of Advanced Nursing, 32(5), 1116-1125.

Institute of Medicine of the National Academies (IOM). (2004). Unequal treatment confronting racial and ethnic disparities in health care. Retrieved September 1, 2011, from Institute of Medicine of the National Academies: http://www.iom.edu

Jacobson, S., Chu, N., Pascucci, M., \& Gaskins, S. (2005). Culturally competent scholarship in nursing research. Journal of Transcultural Nursing, 16(3), 202209.

Jentsch, B. (1998). The "interpreter effect": Rendering interpreters visible in crosscultural research and methodology. Journal of European Social Psychology, 8(4), 275-289. doi:10.1177/095892879800800401

Jones, E., \& Boyle, J. (2011). Working with translators and interpreters in research: Lessons learned. Journal of Transcultural Nursing, 22(2), 109-115. doi:10.1177/1043659610395767

Krueger, R., \& Casey, M. (2009). Focus groups: A practical guide to applied research (4th ed.). Thousand Oaks, CA: Sage Publications.

Leininger, M. (1997). Classic article: Overview of the theory of culture care with the ethnonursing research method. Journal of Transcultural Nursing, 8(2), 32-52.

Leininger, M. (Ed.). (2001). Culture care diversity and universality: A theory of nursing. Boston: Jones \& Bartlett Publishers, Inc. and National League for Nursing.

Leininger, M., \& McFarland, M. (Eds.). (2002). Transcultural nursing: Concepts, theories, research and practice (3rd ed.). New York: McGraw-Hill.

Leininger, M., \& McFarland, M. (Eds.). (2006). Culture care diversity and universality (2nd ed.). Boston: Jones \& Bartlett.

Lincoln, Y., \& Guba, E. (1985). Naturalistic inquiry. Newbury Park, CA: Sage Publications. 
Morgan, D. (1997). Focus groups as qualitative research (2nd ed.). Qualitative Research Methods Series, 16. Thousand Oaks, CA: Sage Publications.

Ngo-Metzger, Q., Massagli, M., Clarridge, B., Manocchia, M., Davis, R., Iezzoni, L., \& Phillips, R. (2003). Linguistic and cultural barriers to care: Perspectives of Chinese and Vietnamese Immigrants. Journal of General Internal Medicine, 18, 44-55.

Nui, N., Davis, A., Bogart, L., Thornbill, T., Abreu, A., Ghazinouri, R., \& Katz, J. (2011). Patient disease perceptions and coping strategies for arthritis in a developing nation: A qualitative study. BMC Musculoskeletal Disorders, 12(228). doi:10.1186/1471-2474-12-228

Ojeda, L., Flores, L., Meza, R., \& Morales, A. (2011). Culturally competent qualitative research with Latino Immigrants. Hispanic Journal of Behavioral Sciences, 33(2), 184-203. doi:10.1177/0739986311402626

Ososki, A., Lohr, P., Reiff, M., Balick, M., Kronenberg, F., Fugh-Berman, A., \& O'Connor, B. (2002). Ethnobotanical literature survey of medicinal plants in the Dominican Republic used for women's health conditions. Journal of Ethnopharmacology, 79, 285-298.

Pabon-Nau, L., Cohen, B., Meigs, J., \& Grant, R. (2010, August). Hypertension and diabetes prevalence among U.S. Hispanics by Country of Origin: The national health interview survey 2000-2005. Journal of General Internal Medicine, 25(8), 847-852.

Purnell, L. (1999). Panamanians' practices for health promotion and the meaning of respect afforded them by health care providers. Journal of Transcultural Nursing, 10(4), 331-339.

Purnell, L. (2001). Guatemalans' practices for health promotion and the meaning of respect afforded them by health care providers. Journal of Transcultural Nursing, 12(1), 40-47.

Schumacher, G. (2010). Culture care meanings, beliefs, and practices in rural Dominican Republic. Journal of Transcultural Nursing, 21(2), 93-103.

Sensor, C. (2006, February/March). Culturally competent care in the workplace. Imprint, 46-50.

Shedlin, M., \& Shulman, L. (2004). Qualitative needs assessment of HIV services among Dominican, Mexican and Central American immigrant populations living in the New York City area. AIDS Care, 16(4), 434-445. 
Siatkowski, A. (2007). Hispanic acculturation: A concept analysis. Journal of Transcultural Nursing, 18(4), 316-323. doi:10.1177/1043365960730593

Smith, B. H. (2011). Problem solving for better health: a global perspective. (B. H. Smith, J. J. Fitzpatrick, \& P. Hoyt-Hudson, Eds.) New York: Springer Publishing Company.

Suurmond, J., \& Seeleman, C. (2006). Shared decision-making in an intercultural context: Barriers in the interaction between physicians and immigrant patients. Patient Education and Counseling, 60(2), 253-259.

U.S. Census Bureau. (2003 a). U.S. Census Bureau. Retrieved August 10, 2006, from Hispanic population reaches all-time high of 38.8 million, new census bureau estimates show: http://www.census.gov/Press-Release/www/2003/cb03100.html

U.S. Census Bureau. (2003 b). U.S. Census Bureau. Retrieved August 10, 2006, from U.S. Census 2000: http://www.census.gov/main/www/cen2000.html

U.S. Census Bureau. (2012, June 12). U. S. Census Bureau: State and County Quickfacts. Retrieved August 8, 2012, from http://quickfacts.census.gov/qfd/states/34/3459190.html

U.S. Department of Health and Human Services . (2010a, January 15). Code of Federal Regulations (CFR); Title 45 Public Welfare, Part 46 Protection of Human Subjects; Section 46.117. Retrieved October 18, 2011, from HHS.gov: http://www.hhs.gov

U.S. Department of Health and Human Services. (2010b, January 15). Code of Federal Regulations; Title 45 Public Welfare, Part 46 Protection of Human Subjects, Section 46.101(b)(2) and (b)(3). Retrieved October 18, 2011, from U.S.Department of Health and Human Services, HHS.gov: http://www.hhs.gov

U.S. Department of Health and Human Services. (2014, January 22). ASPE.hhs.gov Office of The Assistant Secretary for Planning and Evaluation, 2014 Poverty Guidelines. Retrieved January 30, 2015, from http://aspe.hhs.gov/poverty/14poverty.cfm

Vandebroek, I., Balick, M., Ososki, A., Kronenberg, F., Yukes, J., Wade, C., . . . Castillo, D. (2010). The importance of botellas and other plant mixtures in Dominican traditional medicine. Journal of Ethnopharmacology, 128, 20-41. doi:10.1016/j.jep.2009.12.013

Warda, M. (2000). Mexican Americans' perceptions of culturally competent care. Nursing Research, 22, 208-215. 
Williamson, D., Choi, J., Charchuk, M., Rempel, G., Pitre, N., Breitkreuz, R., \& Kushner, K. (2011). Interpreter-facilitated cross-language interviews: a research note. Qualitative Research, 11(4), 381-394. doi:10.1177/1468794111404319

World Health Organization. (2006, October). Constitution of the World Health Organization (45th ed.). Retrieved December 29, 2014, from World Health Organization:

http://www.who.int/governance/eb/who_constitution_en.pdf?ua=1

World Health Organization. (2008). Commission on the Social Determinants of Health Final Report. Retrieved December 29, 2014, from World Health Organization: http://www.whqlibdoc.who.int/hq/2008/WHO_IER_CSDH_08.1_eng.pdf?ua= 1

Yurkovich, E. E., Clairmont, J., \& Grandbois, D. (2002). Mental health care providers' perception of giving culturally responsive care to American Indians. Perspectives in Psychiatric Care, 38(4), 147-156.

Zoucha, R. (1998). The experiences of Mexican Americans receiving professional nursing care: An ethnonursing study. Journal of Transcultural Nursing, 9(2), $34-41$.

Zsemlik, B., \& Fennell, D. (2005, July). Ethnic variation in health and the determinants of health among Latinos. Social Science \& Medicine, 61(1), 5363. 


\section{APPENDICIES \\ Appendix A \\ Example of Interview Inquiry Guide}

1. When do you consider yourself healthy? Or sick? Are your beliefs the same as those of your family, grandparents?

2. Why do people get sick? Is this the same for you?

3. What practices do you use to keep yourself healthy? What practices do you use when you are sick? Are your practices the same as those of your family, grandparents?

4. What do you do when you are sick? Are your practices the same as those of your family, grandparents?

5. Have you experienced care by a doctor, nurse or other health professional in the US in a hospital, clinic or office? Why did you seek their care? How different was this experience from what you expected?

Tell me about experiences that upset you.

Tell me about experiences that you considered good.

6. What sorts of things have made it easier for you and what sorts of things have made it harder for you to get professional health care from doctors, nurses and hospitals in the United States?

How did this make you feel?

What did you do about it? 


\section{Appendix B}

\section{Confidentiality Agreement for Interpreters}

I understand that as an interpreter for a study being conducted by Constance Sobon Sensor, MSN, RN, Department of Behavioral Sciences, Community and Health Systems, in the College of Nursing, Seton Hall University, under the supervision of

Judith Lothian, $\mathrm{PhD}, \mathrm{RN}$, I am privy to confidential information. I agree to keep all data collected during this study confidential and will not reveal it to anyone outside the research team.

Printed Name of Interpreter

Signature of Interpreter

Date

Signature of Witness

Date 


\section{Appendix C \\ Recruitment Script for Outreach Workers}

Constance Sobon Sensor, is a $\mathrm{PhD}$ candidate at Seton Hall University College of Nursing, Department of Behavioral Sciences, Community and Health Systems. She is a nurse who wants to study Dominicans living in the United States. She wants to ask you questions to learn about Dominican beliefs and practices related to health, and your experiences with professional health care. This research may help to improve health care for Dominicans living in the United States. If you want to participate, this study will require you to meet with Mrs. Sensor and two Spanish interpreters, along with a group of other Dominicans in a focus group two or three times, for up to two hours each time, over two or three months. As you think about whether or not you want to be a part of this study, you should know the following:

Your participation in this study is completely voluntary, and you can stop participating in the study at any time with no consequences to you. Mrs. Sensor will audio-record your interviews with her. She will have a Dominican interpreter with her to ask the questions if you do not speak English. The information you give to Mrs. Sensor will be confidential, that means it will not be shared with anyone but the research team. Your name and identity will not be connected to your answers in any way, at any time. You do not have to sign your name on any papers to participate in this study. 
When you finish participating in the last part of the study, you will receive a $\$ 25$ gift card. If you volunteer to participate, we will arrange for a private area for you to talk to Mrs. Sensor with your group. If you want to talk in Spanish, a Dominican interpreter will also be present. Mrs. Sensor will come and talk to you if you are interested in being part of the study. Mrs. Sensor will explain more about the study and answer your questions. You can decide then if you want to participate in the study.

If you say yes, you want to be a part of this study; Mrs. Sensor will make sure you understand what is required of you to be a part of this study, before she asks any questions related to the research. The requirements will be read to you in Spanish before you agree to participate in the study.

The findings from this study may change care for Dominicans living in the United States. Mrs. Sensor will be happy to answer any questions that you have about this important study. If you are not sure, you can decide if you want to participate in the study after you meet Mrs. Sensor. You can ask people from your family or your friends who are Dominican if they would like to participate too. When I am finished talking to you, please let me know if you are interested in talking to Mrs. Sensor about what you do when you are sick, what you do to stay well and how you feel about doctors, nurses and hospitals that take care of you in the United States. Then, you can meet Mrs. Sensor at (Place) at (time). I will invite her to meet with us. 


\section{Appendix D}

\section{Demographic Survey Questions}

Participant Number:

How long did you live in the Dominican Republic?

What language do you speak at home?

Are you comfortable talking about health issues with a mixed group of men and women? Yes No

How old are you?

What is your gender? Male Female

Are you married? Yes No

How many children do you have?

How many years did you go to school? __ What grade did you finish?

Can you read? Yes No What language(s) do you read?

Can you write? Yes No What language(s) do you write?

What kind of work did you do in the Dominican Republic?

What kind of work do you do in the United States?

Have you visited a doctor or a nurse or been in the hospital in the United States because you were sick or because you were taking care of someone who was sick? Yes No

Do you own a car? Yes No

How many people live with you in your home?

How many people in your home help to pay the bills?

What is the annual income for all of the people your household?

less than $\$ 10,000$ $\$ 30,001$ to $\$ 40,000$
$\$ 20,001$ to $\$ 30,000$ more than $\$ 50,000$ 


\section{Appendix E}

\section{Approval from Institutional Review Board}

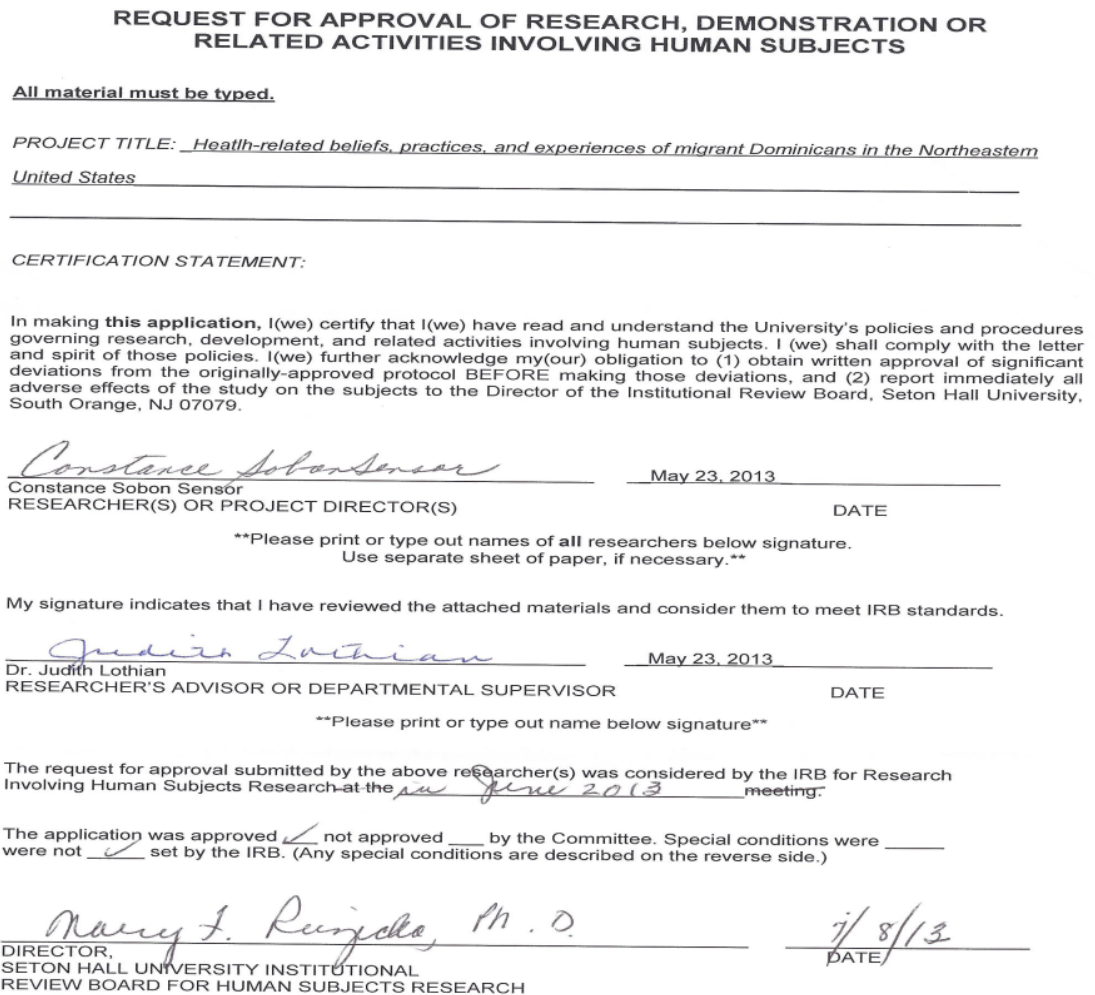




\title{
$\frac{\text { SETON HALL }}{\ln _{\mathrm{s}} \mathrm{s}}$
}

May 13, 2014

\author{
Constance Sobon Sensor \\ 2284 Old Farm Road \\ Scotch Plains, NJ 07076 \\ Dear Ms. Sobon-Sensor,
}

The Seton Hall University Institutional Review Board has reviewed your Continuing Review application for your research proposal entitled "Health-related Beliefs, Practices and Experiences of Migrant Dominicans in the Northeastern United States".

You are hereby granted another 12-month approval, effective July 8, 2014 for follow-up subjects and data analysis only. Your new stamped Consent Forms are enclosed.

If any changes are desired in this protocol, they must be submitted to the IRB for approval before implementation.

Thank you for your cooperation.

Sincerely,

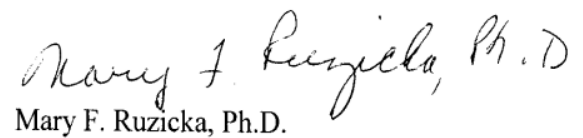

Professor

Director, Institutional Review Board

cc: Dr. Judith Lothian

Dr. Phyllis Hansell 


\title{
Appendix F
}

\section{Informed Consent in Spanish}

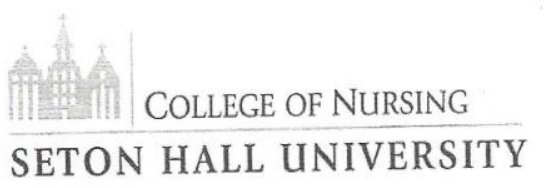

\author{
Seton Hall University \\ Institutional Review Board
}

JUL 082014

Approval Date

\section{Consentimiento y Información de el Estudio}

Afiliación de Investigador

La investigadora, Constance Sobon Sensor es una candidata a doctorado con la escuela de enfermería de la universidad Seton Hall. La Señora Sensor esta conduciendo un estudio llamado: "Creencias relacionadas con la salud, prácticas y experiencias de los inmigrantes Dominicanos en el noreste de Los Estados Unidos."

Propósito y Duración del el Estudio

El propósito del estudio es aprender las creencias relacionadas con la salud, prácticas y experiencias de la personas de la Republica Dominicana viviendo in el noreste de los Estados Unidos. Los participantes se reunirán dos a tres veces para hablar en grupos con otros Dominicanos por dos o tres meses. Cada reunión puede durar entre una o dos horas.

Procedimiento

Durante este estudio, la investigadora va a hablar con grupos de participantes Dominicanos sobre las creencias y practicas relacionado con la salud y las experiencias con doctores, enfermeras y hospitales en Los Estados Unidos. Por ejemplo, una pregunta que la investigadora va a preguntar a los participantes es que describa lo que el participante hace para mantenerse saludable. La discusión será audio grabado y la investigadora puede coger notas. La investigadora va a usar un intérprete para preguntar las preguntas en Español. Las discusiones en grupos se llevaran a cabo en un tiempo y lugar que sea agradable mutuamente para los investigadores y los participantes.

\section{Grabación de Audio}

Las entrevistas va a hacer conducidas por la investigadora y intérpretes bilingües, y la conversación va a hacer audio-grabada. Nadie va a ser identificado en la grabación. Después de la entrevista, las grabaciones serán transcritas en Inglés. El contenido de las entrevistas serán guardadas en llaves de memoria USB, junto con las grabaciones, todo estará en un archivo bajo llave en la casa de la investigadora. La investigadora es la única que tiene llave para el archivo. Los intérpretes y los traductores mantendrán toda la información grabada confidencial y privada, y no compartir esa información con nadie más que el equipo de investigación. Las grabaciones serán guardadas por al menos 3 años.

Carácter Voluntario de la Participación

Los participantes no están obligados a participar en el estudio, es completamente voluntario. Los participantes no tienen que responder a cualquier pregunta que no quiere responder durante la discusión del grupo. Los participantes son libres de retirar sus consentimientos y dejar de participar en el estudio, en cualquier momento, sin consecuencias para ellos.

400 South Orange Avenue $\cdot$ South Orange, New Jersey 07079-2693 - wwvushu.edu 
Seton Hall University

Institutional Review Board

JUL. 082014

Confidencialidad

Approval Date

Toda la información colectada durante este estudio y archivos de los datos serán confidenciales. El nombre del participante nunca aparecerá en ningún reporte de investigación para este estudio. La investigadora garantiza que los participantes no van a ser identificados por nombre y no habrá manera que pueda ser identificada(o) por sus respuestas grabadas a las preguntas de la entrevista. Palabras exactas podrán ser usadas en los resultados en el reporte del estudio, pero los nombres de los participantes nunca se van a usar. Todos los materiales escritos y formularios de consentimientos estarán guardados en un archivador bajo llave en la casa la investigadora. Toda la información que se recoge en este estudio se mantendrá en una llave de memoria USB, encerrada en un archivador en la casa del investigador. Nada mas la investigadora va a tener acceso a el archivador. Cualquier intérpretes y traductores que este asistiendo en este estudio firmaran un acuerdo de confidencialidad y no tendrá acceso a los nombres de los participantes.

\section{Riesgos y Molestias}

No hay riesgos conocidos o esperados por participar en el estudio, sin embargo, hay una pequeña posibilidad de que alguna pregunta hecha en grupo de discusión pueda molestarle. Si hay una pregunta que le molesta, no tiene que responder la pregunta. Si la discusión del grupo le cause angustia para un participante, él o ella puede buscar la ayuda de una clínica de salud comunitaria. Las siguientes clínicas están disponibles sin costo alguno o a un costo muy bajo, dependiendo de los ingresos personales:

Neighborhood Health Center Plainfield, 1700 Myrtle Ave., Plainfield, NJ 908-753-6401

Perth Amboy Housing Authority, 415 Fayette St., Perth Amboy, NJ 732-324-0500

NHCAC Health Center @ Passaic, 110 Main Ave., Passaic, NJ 973-777-0256

\section{Beneficios}

Aunque no hay beneficios directos por participar en este estudio, es posible que se produzcan cambios en los cuidados de enfermería a los Dominicanos en Los Estados Unidos después de que se complete el estudio. Este estudio tiene el potencial de aumentar los conocimientos sobre las creencias relacionadas con la salud y las prácticas tradicionales de los Dominicanos en Los Estados Unidos que se pueden enseñar a las enfermeras que le dan cuidados de salud profesionales a los Dominicanos.

\section{Compensación}

No va a ser compensado por participar en este estudio. Si usted acepta participar en este estudio de principio a fin, que puede requerir múltiple sesiones, recibirá una tarjeta de regalo de $\$ 25.00$ cuando la última sesión está completa. 
Información de Contacto

Seton Hall University
Institutional Review Board

JUL 082014

Approval Date

RN en la Universidad Seton Hall, Escuela de Enfermería, 400 South Orange Ave, South u Orange NJ 07079 (973-761-7949) o Email: sensorco@shu.edu. También puede contactar a la Doctora Judith Lothian, RN, Faculty Advisor, en la Universidad Seton Hall, Escuela de Enfermería, (973-761-9273). Si usted tiene alguna pregunta sobre sus derechos como participante, o sobre la forma en que el estudio se lleve a cabo, debe comunicarse con Mary Ruzicka, PhD, Directora de la Oficina de la Junta de Revisión Institucional de la Universidad Seton Hall, (973-313-6341).

\section{Consentimiento}

Este formulario de consentimiento ha sido leido para mí, o yo he leído este formulario, y entiendo lo que se está pidiendo de mí al participar en este estudio de investigación de Constance Sobon Sensor, titulado "Las creencias relacionadas con la salud, Prácticas y Experiencias de Dominicanos inmigrantes en el noreste de Estados Unidos." Yo también entiendo que mi participación es voluntaria y que soy libre de retirar mi consentimiento en cualquier momento y por cualquier razón. Después de firmar este consentimiento, me darán una copia para mis archivos y referencias futuras.

En estos términos, certifico que estoy dispuesto a participar en este estudio de investigación, y estoy de acuerdo que mis conversaciones con la investigadora y el grupo de discusión serán audio-grabado.

Numero asignado del Participante

Firma/ Marca del Participante

Testigo de la firma del Participante, imprima el nombre

Firma del Testigo

\section{Fecha}

\section{Fecha}

Fecha

El consentimiento para participar se indica mediante el regreso de la forma demográfica y el formulario de consentimiente a la investigadora, con mi número asignado en el formulario demográfico. 


\title{
Appendix G
}

\author{
Informed Consent in English
}

\section{II.] COLLEGE OF NURSING SETON HALL UNIVERSITY}

\author{
Seton Hall University \\ Institutional Review Board
}

JUL 082014

Approval Date

\section{Informed Consent}

Researcher's Affiliation

The researcher, Constance Sobon Sensor, is a PhD candidate at Seton Hall University College of Nursing. She is conducting a study called "Health-related beliefs, practices, and experiences of migrant Dominicans in the Northeastern United States."

\section{Purpose and Duration of the Study}

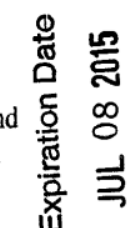
experiences of people from the Dominican Republic living in the Northeastern United States. Participants will meet two to three times, to talk in focus groups with other Dominicans, over two or three months. Each meeting time may last from one to two hours.

\section{Procedure}

During this study, the researcher will talk to groups of Dominican participants about their beliefs and practices related to health, and their experience with doctors, nurses, and hospitals in the United States. For example, one question the researcher will ask the participants is to describe what they do to stay healthy. The discussion will be audiorecorded and the researcher may take some notes. The researcher will use an interpreter to ask the questions in Spanish. The group discussions will take place at a time and place that is mutually agreeable to the participants and the researcher.

\section{Audio-Recording \\ The interviews will be conducted by the researcher and bilingual interpreters, and the conversation will be audio-recorded. No one will be identified in the recording. After the interview has ended, the recordings will be transcribed into English. The transcribed interviews will be kept on USB memory keys, along with the recordings, in a locked file in the researcher's home. The researcher will have the only key to the file. The interpreters and translators will keep all of the recorded information confidential and private, and will not share that information with anyone else but the research team. The recordings will be kept for at least 3 years.}

\section{Voluntary Nature of the Participation}

Participants are under no obligation to participate in this study, it is completely voluntary. Participants do not have to answer any question that they do not want to answer during the focus groups. Participants are free to withdraw their consent and to stop participating in the study at any time with no consequences to them. 


\section{Seton Hall University Institutional Review Board}

\section{JUL 082014}

\section{Approval Date}

\section{Confidentiality}

All information collected during this study and records of the data will be confidential. The participant's name will never appear on any research reports from this study. The researcher guarantees that the participants will not be identified by name and that there will be no way for anyone to identify participants from their recorded answers to the interview questions. Exact words may be used in reporting results of this study, but the participant's names will never be used. All written materials and consent forms will be stored in a locked file cabinet in the researcher's home. All information that is gathered from this study will be kept on a USB memory key, locked in a file cabinet in the researcher's home. Only the researcher will have access to the locked file cabinet. Any interpreters or translators that assist in this study will sign a confidentiality agreement and will not have access to the participants' names.

\section{Risks or Discomforts}

There are no known or anticipated risks for participating in this study, but there is a small chance that the group discussion will be distressing to a participant. If a discussion question distresses a participant, he or she does not have to answer the question. If a participant is very distressed by the question, he or she can seek help from a community health clinic. The following clinics are available at no cost or at a very low cost, depending on one's income:

Neighborhood Health Center Plainfield, 1700 Myrtle Ave., Plainfield, NJ 908-753-6401

Perth Amboy Housing Authority 415 Fayette St., Perth Amboy, NJ 732-324-0500

NHCAC Health Center@Passaic, 110 Main Ave., Passaic, NJ 973-777-0256

\section{Benefits}

Although there are no direct benefits to participating in this study, it is possible that changes will occur in nursing care for Dominican people in the United States after this study is completed. This study has the potential to increase knowledge concerning the traditional health-related beliefs and practices of Dominicans in the United States that can be taught to nurses who provide professional health care to Dominican people.

\section{Compensation}

You will not be financially compensated for participating in this study. If you agree to participate in this study from beginning to end, which may require several meetings, you will receive a $\$ 25.00$ gift card when the last session is completed. 


\section{Contact Information}

If you have any further questions about participation in this study, you may call the principal investigator for this study, Constance Sobon Sensor, MSN, RN, at Seton Hall University, College of Nursing, 400 South Orange Avenue, South Orange, NJ 07079 RN, Faculty Advisor, Setonsorco ashu.edu. You may also contact Dr. Judith Lothian, RN, Faculty Advisor, Seton Hall University, College of Nursing, (973-761-9273). If you have any questions about your rights as a participant, or about the way the study is conducted, you should contact Mary Ruzicka, PhD, Director, Office of Institutional Review Board, Seton Hall University, (973-313-6341).

\section{Consent}

This consent form has been read to me, or I have read this consent form myself, and I understand what is being requested of me to participate in this research study by Constance Sobon Sensor, entitled "Health-related Beliefs, Practices and Experiences of migrant Dominicans in the Northeastern United States." I also understand that my participation is voluntary and that I am free to withdraw my consent at any time, for any reasons. After I sign this consent, I will be given a copy of it for my records and future reference. On these terms, I certify that I am willing to participate in this research project, and I agree to have my conversations with the researcher and the focus discussion group audio-recorded.

Participant's Assigned Number (printed)

Participant's Mark
Witness to participant's mark, printed name

Witness signature

\begin{tabular}{|c|c|}
\hline Date & $\begin{array}{l}\stackrel{\Phi}{\tilde{\varpi}} \\
\text { న }\end{array}$ \\
\hline Date & 竞 \\
\hline
\end{tabular}

Consent to participate is indicated by returning the attached demographic survey to the researcher with my assigned number on the form.

Seton Hall University Institutional Roviow Board

JUL 082014

Approval Date 
